Alma Mater Studiorum - Università di Bologna DEPARTMENT OF ECONOMICS

\title{
Trade, externalities, and the impact of asymmetric information on trade policy
}

Giuseppe Francesco Gori Luca Lambertini

Quaderni - Working Paper DSE $N^{\circ} 930$

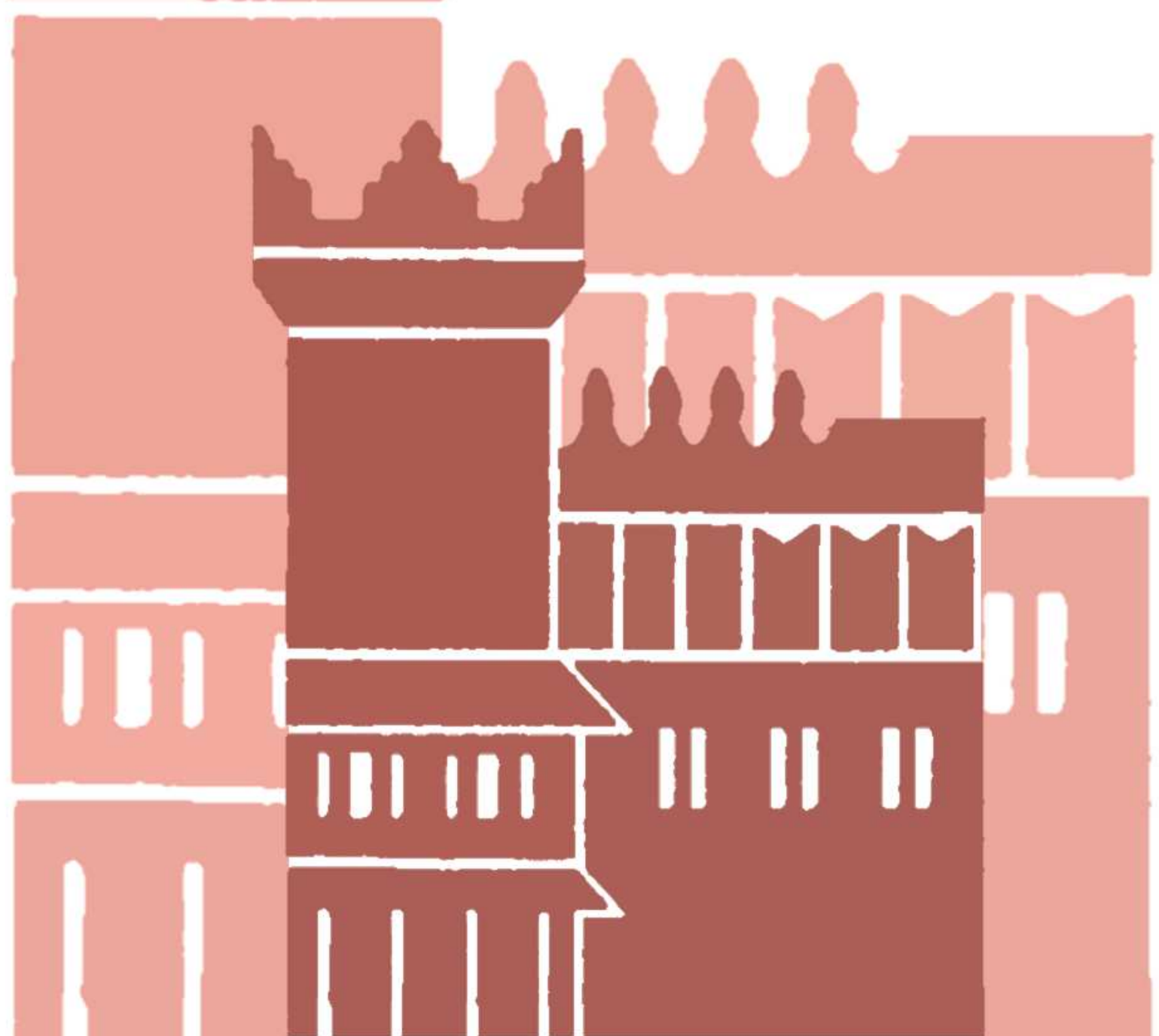




\title{
Trade, externalities, and the impact of asymmetric information on trade policy*
}

\author{
Giuseppe Francesco Gori ${ }^{\dagger}$, Luca Lambertini $\ddagger \S$ \\ March 10, 2014
}

\begin{abstract}
This paper investigates the relationship between trade liberalisation, consumers' environmental awareness and a negative environmental externality in consumption. We adopt an international Hotelling duopoly setup, where firms are located in two asymmetric countries. We find that, if the intensity of environmental externality is common knowledge for country governments, this setup delivers no need of accompanying trade policies in order to enforce trade liberalisation. In the opposite case, in which information is asymmetric, i.e., the small country's Government cannot observe the positive enviromental effects of its firm's exports to foreign consumers, we find that: (i) the Pareto optimum is always enforced, since the brown country always relaxes the distortionary trade policy, and (ii) cheating on the environmental externality allows the brown country's government to extract extra surplus from the green country. Allowing for trade in green technology delivers opposite conclusions: the externality is minimised and welfare is maximised in equilibrium if information is symmetric while trade liberalisation with asymmetric information always entails a second best outcome.
\end{abstract}

JEL classification: F12, L13, H23

Keywords: international trade, spatial competition, environmental externality, asymmetric information, green technology

\footnotetext{
${ }^{*}$ We would like to thank Gianmarco Ottaviano and Giovanni Peri for very helpful comments and suggestions on earlier drafts. The usual disclaimer applies.

${ }^{\dagger}$ Regional Institute for the Economic Planning of Tuscany (IRPET). Villa La Quiete alle Montalve, Via Pietro Dazzi 1, 50141 Firenze, Italy.

¥Department of Economics, University of Bologna, Strada Maggiore 45, 40125 Bologna, Italy.

$\S$ The Rimini Centre for Economic Analysis (RCEA). Via Patara 3, 47900 Rimini, Italy

`Corresponding author: luca.lambertini@unibo.it.
} 


\section{Introduction}

Despite the large research effort of the past two decades, the relationship between trade openness and enviromental impact of production/consumption is still far from being fully identified and, under several respects, it still represents a challenging issue for economists. A large part of this effort has built a view ${ }^{1}$ according to which trade is often claimed to be the cause of short-run asymmetric environmental effects that - if adequately taken into account by countries' governments - may pose a serious threat to the bilateral opening of commercial frontiers. ${ }^{2}$ A relevant number of contributions have in fact investigated the way governments shape their environmental policies in order to contrast or even reinforce the effects of trade and trade policies. ${ }^{3}$

On the contrary, fewer works have investigated the case in which the reverse holds, that is trade policies are used to meet environmental goals. This is equivalent to ask whether environmental issues exert any effect on countries' bilateral terms of trade, even supposing that no environmental policy can be undertaken. This case may occur, for instance, as a consequence of the high political and administrative costs associated to environmental policies, especially to those encompassing the control of polluting emissions. Furthermore, note that these costs are likely to be higher for the poorer or the less developed among the trading countries, the latter being also those where the environmental awareness of citizen/consumers has less likely been developed. If this were the case, trade policies, e.g. the creation of trade barriers, could be the cheapest and most effective tools a government might use to maximise social welfare.

The latter case is indeed the one tackled by our contibution. We rely on a two-country international Hotelling duopoly where countries are asymmetric, in the light of [20], [34] and [16]. In our view, country size is synonym of population size and, accordingly, we identify the larger country as the poorest/less developed one, hosting the only polluting firm in the economy and being endowed with an environmentally unaware population. ${ }^{4}$ On the contrary, the smaller country is green from the outset, meaning that it has an environmentally aware population and a firm producing a green good. In our setup, all the citizens of a given country - whether they are environmentally aware or not - suffer from a negative externality which stems from the national consumption of the brown

\footnotetext{
${ }^{1}$ To this regard, a notable issue is the distinction between short-run and long-run trade environmental effects, which claims for a deep investigation of the relationship between trade, growth and environment. To this regard, several empirical contributions support the environmental Kuznets theory, according to which the long-run effect of trade may result as positive. A basic explanation for this is that trade boosts countries' GDP growth process, thereby also accellerating the process of "green" technological innovation/adoption. According to the scheme proposed by [1], in fact, the aggregate effect of trade depends on the sign and the magnitude of the so-called "scale", "technique" and "composition" effects. To this regard, see, beetween others, [14], [23], [6] and [7].

${ }^{2}$ To this regard, remarkable contributions are [9] and [33].

${ }^{3}$ To this regard see, for instance, [28], [18], [24] and [2]. These works are mainly focused on the interplay between environmental standards and trade, addressing, in most of the cases, the question of how standards are handled by countries' governments in light of their associated trade effects. Here, the research has been largely motivated by the social and environmental concern about the trade-induced race-to-the-bottom in the environmental regulation of sovereign states.

${ }^{4}$ Our model includes a very simple modelisation of environmental awareness, which, however, is reminiscent of previous important contributions such as [8]. Other important related contributions are [30], $[5],[35],[11],[26],[3]$ and [12].
} 
good.

Our model is therefore suitable for investigating some crucial questions. Is, in this context, trade liberalisation raising or lowering the world welfare? Does free trade entail symmetric or asymmetric environmental effects? Does environmental awareness play any role? Do countries actually recur to trade policies? How much are these policies distortionary? Can trade liberalisation deliver both the social and the environmental first best?

Moreover, our setup fits the purpose of approaching two additional relevant issues. The first one concerns the role of asymmetric information, which is central in the strategic approach to international trade. ${ }^{5}$

If the emission intensity (i.e., the magnitude of the negative environmental externality) is private information, we can suppose that governments may cheat on its level. Depending on other conditions, in fact, the trade agreements may involve side payments/compensations in favour of the countries which lose from trade liberalisation. Thus, if we suppose that trade impacts on welfare also throught the environment, cheating on the level of trade-induced environmental effects may condition the opening of trade barriers and/or may affect countries' free trade equilibrium welfare. Moreover, as underlined by [25], overreporting losses may cause the persistency of distortionary policies: policy makers of the "winning" country do not drop such policies as they would incur the risk of overcompensating the losers.

The second issue is the role of trade in the diffusion of green technologies. This point is widely recognized in the literature: free trade promotes efficiency in production (i.e. the reduction of energy use per unit of output) which entails the replacement of old, highpolluting plants. The development of green (clean) production technologies and their adoption by polluting industries is usually considered as a long-run effect of trade openess since it is supposed to emerge at late stages of a coutry's economic development.

However, this issue has almost ever been tackled from the point of view of environmental regulation: trading nations may come under internal or external (international) pressure to either adopt or tighten environmental standards, and environmental regulation stimulates green technology innovation and/or the adoption of existing green technologies by existing firms. ${ }^{6}$

We tackle the problem by assuming that countries' governments can trade in technology in order to maximise the welfare of their respective countries. In our model, who buys technology reduces the potential environmental damage, by lowering the emission intensity of national brown good's consumption. In other words, we do not model any firms' compliance behaviour to green production standards: when governments buy technology, they freely transfer it to national firms or, equivalently, they directly use it to abate emissions $^{7}$ or to mitigate the negative environmental effects of production. We adopt such an assumption since we want to focus as clearly as possible on the interplay between trade in technology, trade liberalisation in the Hotelling-style differentiated good and asymmetric information on the emission intensity. In particular, we ask whether governments' incentives to transfer technology may be compromised by rent-seeking motives associated with

\footnotetext{
${ }^{5}$ See, for instance, [4], [27], [17], [10] and [22].

${ }^{6}$ To this regards, [19], [31], [29], [21] and [13].

${ }^{7}$ For instance, by directly intervening in the national power sector.
} 
trade flows and the resulting environmental consequences.

Our framework delivers clearcut results. First of all, taking the environment into account naturally fosters trade integration rather than preventing it. As a consequence, free trade occurs with no need of accompanying policies. ${ }^{8}$

Second, the world social welfare is maximised in correspondence of the green autarky, where the environmental effect of consumption is null in both countries and national firms, whether green or brown, behave as monopolists. Accordingly, trade liberalisation is always a second best equilibrium. Third, asymmetric information on the relevant environmental parameter rules out the use of any possible distortionary trade policy (the government of the larger country may adopt a distortionary import tariff in order to avoid the risk of not being adequately compensated for the loss suffered in free trade, thus lowering overall welfare).

Finally, while trade in the green technology always enforces the attainment of world's social welfare first best level, which coincides with green autarky, asymmetric information always prevents the brown country from buying green technology, thereby necessarily enforcing a second best equilibrium.

The remainder of the paper is structured as follows. Section 2 sets out the basic model, the autarkic equilibrium and the the effects of trade liberalisation. Section 3 shows how different trade policies affect the long run social welfare of both countries. Section 4 considers whether asymmetric information on the level of emissions dampens the overall equilibrium social welfare. Section 5 introduces a market for the green technology and endogenise the emisison level. Section 6 sums up our analysis.

\section{The model, autarky and free trade}

Our setup is as follows. Two firms operate in a linear world of unit length where firm 1 is located in country 1 and firm 2 in country 2. Consumers are uniformly distributed over $[0,1]$ with density 1 and a share $\alpha$ of them belongs to country 1 while the complement to 1 belongs to country 2 . Since $\alpha$ is to be intended as the border, asymmetry in country sizes is assured by limiting it to the interval $(0,1 / 2)$ so that country 1 is smaller than country 2. A constant marginal cost of production is common to both firms ${ }^{9}$ and no relocation costs are modeled. In order to take the negative environmental externality into account, we also model a linear damage function, such that country $i$ 's social welfare is reduced by an amount $D_{i}$ which is equal to:

$$
D_{i}=\beta y_{2 i} \quad \text { with } \quad i=1,2,
$$

where $y_{2 i}$ is country $i$ 's total consumption of the brown good produced by firm 2 while $\beta \in[0,1]$ represents the emission intensity. In both countries, each consumer has a unit

\footnotetext{
${ }^{8}$ Our setup can be contrasted with [16] that analyze a similar case in which free trade without accompanying trade policies is undoubtedly detrimental at the world level, both from the environmental and the social point of view. In that case, in fact, (i) trade always implies an increase in the consumption of a brown good and (ii) a decrease of the importing country's social welfare not counterbalanced by an increase in the exporting country's one. At the same time, an export subsidy for the firm producing the green variety may turn the overall welfare balance positive, provided that the negative externality stemming from the consumption of the brown good is high enough.

${ }^{9}$ Here assumed to be nil without loss of generality.
} 
demand and consumption yields a constant positive surplus $s$. Net utility, however, may or may not account for pollution, depending on the location of a specific consumer. Consider first an individual based in country 2. For him/her, net utility is defined as:

$$
U_{2}=s-t d_{i}^{2}-p_{i}, \quad i=1,2,
$$

where $p_{i}$ is the price of variety $i$ and $t d_{i}^{2}$ is the transportation cost, quadratic in distance $d_{i}$ from firm $i$. The distance is defined as:

$$
d_{i}=m-x_{i},
$$

where $m$ and $x_{i}$ are, respectively, the generic consumer's and firm $i$ 's locations.

Looking instead at the environmentally concerned consumer, which is necessarily based in country 1 , the corresponding net surplus is defined as:

$$
U_{1}=s-t d_{i}^{2}-p_{i}-D_{1}, \quad i=1,2,
$$

where $D_{1}=0$ in autarky. For the sake of simplicity, and without further loss of generality, we also normalize the transportation cost rate $t$ to one while the total transportation costs in each country write as:

$$
T C_{1}^{j}=\int_{0}^{\widehat{m}_{j}}\left(d_{1}\right)^{2} d m ; \quad T C_{2}^{j}=\int_{\bar{m}}^{1}\left(d_{2}\right)^{2} d m
$$

where $j=A, T$ whether we refer to the autarkic or to the free trade equilibrium. In (2.5) $\widehat{m}_{j}$ identifies the location of the marginal consumer and writes as $\hat{m}_{A}=\alpha$ in autarky and $\hat{m_{T}}$ in free trade. Transportation costs of course also appear in the definition of consumer surpluses:

$$
C S_{1}^{j}=\int_{0}^{\widehat{m}_{j}}\left[s-p_{1}-\left(d_{1}\right)^{2}\right] d m ; \quad C S_{2}^{j}=\int_{\widehat{m}_{j}}^{1}\left[s-p_{2}-\left(d_{2}\right)^{2}\right] d m .
$$

In autarky, the monopoly price set by each firm nullifies the net surplus $U_{i}$ of the marginal consumers, i.e., those living at country borders $0, \alpha$ or 1 :

$$
p_{1}^{A}=s-\left(\alpha-x_{1}^{A}\right)^{2} ; \quad p_{2}^{A}=s-\left(1-x_{2}^{A}\right)^{2},
$$

where the socially optimal locations are $x_{1}^{A}=\alpha / 2$ and $x_{2}^{A}=(\alpha+1) / 2$. As for free trade, according to [16], the position of the indifferent consumer is

$$
\hat{m}_{T}=\frac{p_{1}^{T}-p_{2}^{T}+\left(x_{1}^{T}\right)^{2}-\left(x_{2}^{T}\right)^{2}}{2\left(x_{1}^{T}-x_{2}^{T}\right)}
$$

which is independent of emission intensity $\beta$. That is, since consumers in country 2 incorporate the environmental externality irrespectively of their consumption choice (whether green or brown), the volume of firm 1's exports to country 2 is unaffected by the environmental awareness of the recipients.

Accordingly, the two-stage subgame perfect equilibrium in pure strategies coincides with [20], with maximum differentiation at $x_{1}^{T}=0, x_{2}^{T}=1$, equilibrium prices and profits $p_{1}^{T}=p_{2}^{T}=t=1, \pi_{1}^{T}=\pi_{2}^{T}=\frac{t}{2}=\frac{1}{2}$ and $\hat{m}_{T}=\frac{1}{2}$. 
Note that, since green consumers do not suffer from the externality while brown ones by definition disregard it, consumer surplus is defined as in (2.6), and the externality caused by firm 2's activity is accounted for in the definition of country 2's welfare (that is, one needs to suppose that country 2's government takes into account the externality although its citizens do not):

$$
S W_{1}^{j}=\pi_{1}^{j}+C S_{1}^{j} ; \quad S W_{2}^{j}=\pi_{2}^{j}+C S_{2}^{j}-\beta(1-\bar{m}) .
$$

Also observe that while the social welfare of country 2 is negatively affected by the consumption of the brown good $\left(y_{22}^{j}=1-\bar{m}\right)$, this does not affect the social welfare of country 1 (since the externality is generated by consumption, no transboundary pollution is supposed to exist). Moreover, in autarky, non negativity of both prices requires imposing a condition on the level of gross consumer surplus common to all consumers, which is:

$$
s \geq s_{p}^{A}=\frac{1}{4}[1+\alpha(\alpha-2)] .
$$

Under free trade, no additional condition on $s, \alpha, \beta$ is required to ensure the non-negativity of prices and profits while a new condition on gross surplus must hold in order for full market coverage to be sustainable, i.e.,

$$
s \geq s_{M C}^{T}=\frac{1}{4}(5+2 \beta)
$$

where

$$
s_{M C}^{T}>s_{p}^{A} \quad \forall \alpha \in(0,1 / 2), \beta \in(0,1),
$$

so that the condition for market coverage in the long run also assures non-negativity of prices in autarky.

We refer the reader interested in the details of all the magnitudes relative to the autarkic and free trade cases to Appendices A.1 and A.2, and move forward to depict the framework of gain and losses stemming from the opening to trade. To this regard, the following propositions summarise how trade liberalisation affects the social welfare in both countries.

Proposition 1 [Welfare] Trade liberalisation causes (i) an increase in the welfare of the smaller country if the latter is sufficiently small, (ii) a decrease in the welfare of the larger country, (iii) an increase in the welfare at the world level for sufficently small $\alpha$ and sufficiently high $\beta$.

Proof. In order to prove part (i) of Proposition 1 is sufficient to observe that:

$$
S W_{1}^{T}-S W_{1}^{A}=\frac{1}{4}\left[2-\alpha\left(4+\alpha^{2}\right)\right]>0 \quad \text { iff } \quad \alpha \in(0,0.4735)
$$

while, for what concerns part (ii)

$$
S W_{2}^{T}-S W_{2}^{A}=\frac{1}{4}\left[\alpha\left(3+\alpha+\alpha^{2}-4 \beta\right)-2(1-\beta)\right]
$$

which is strictly negative over the admissible range of parameters $\alpha$ and $\beta$. As to part (iii), the welfare differential at the world level is: 


$$
S W^{T}-S W^{A}=\frac{1}{4}[\alpha(\alpha-4 \beta-1)+2 \beta]>0 \quad \text { iff } \quad \alpha \in(0,0.4385), \frac{\alpha(1-\alpha)}{2-4 \alpha}<\beta<1
$$

where $S W^{j}$ is social welfare at the world level.

Proposition 1 thus implies that, when the polluting good is produced in the larger country, trade liberalisation may be, per se, welfare improving at the world level.

The elementary intuition for this result is that, if the brown firm is based in the larger country and the position of the indifferent consumer under trade liberalisation is independent of the location of the brown production, then free trade implies that the green firm necessarily penetrates the larger country and therefore some consumers in the latter have access to the green good. This reshuffling of aggregate demand at the world level in favour of the green variety reduces global pollution and opens the way to a welfare increase at the world level.

Figure 1 presents a picture of the parameter space defined above, where $\Delta S W_{i}^{A, T}$ indicates the value of the social welfare differential from the autarkic equilibrium to the free trade equilibrium in country $i$.

[Figure 1 about here]

Hence, since free trade is unambiguously detrimental for the larger country (regardless of size asymmetry and emission intensity), opening its frontiers to trade is a strictly dominated strategy for the latter. Notwithstanding this, in case the gain in social welfare for the smaller country is high enough to compensate for the loss borne by the larger one, trade liberalisation is likely to occur when allowing for side payments.

In a supergame played over an infinite horizon, this problem could be effectively solved to generate a Pareto-efficient outcome. Applying the perfect folk theorem as in [15], the relevant condition is:

$$
\frac{1}{1-\delta}\left(\Delta S W_{1}^{A, T}-T r_{1,2}\right) \geq \Delta S W_{1}^{A, T}+\frac{\delta}{1-\delta} S W_{1}^{A}
$$

where $\operatorname{Tr}_{1,2}$ is the required side payment from country 1 to country 2 . It is straightforward to show that $(2.16)$ requires

$$
\delta \geq \hat{\delta}_{1}=\frac{T r_{1,2}}{S W_{1}^{T}-2 S W_{1}^{A}} .
$$

Condition (2.17) reveals that $S W_{1}^{T}<2 S W_{1}^{A}$ suffices to ensure the sustainability of the Pareto-efficient equilibrium outcome at the subgame perfect equilibrium of the supergame. The latter condition is trivially shown to hold for each $\alpha, \beta$ and $s>\frac{3-6 \alpha-\alpha^{3}}{6 \alpha}$.

The analysis of trade liberalisation effects on the social welfare also suggests the following:

Proposition 2 [Social and Environmental First Best] For any size of the smaller country, (i) the highest possible social welfare at the world level is met when the emission intensity is null, and (ii) trade liberalisation never maximises overall social welfare. 
Proof. In order to prove the first part of the proposition it is sufficient to observe that, from (2.15), the derivatives with respect to $\beta$ of both $S W^{A}$ and $S W^{T}$

$$
\frac{S W^{A}}{\partial \beta}=\alpha-1 ; \quad \frac{S W^{T}}{\partial \beta}=-\frac{1}{2},
$$

are strictly negative for all $\alpha \in(0,1 / 2)$. Moreover, (2.18), together with (2.15), implies the second claim in the proposition.

Proposition 2 entails that the maximum social welfare is necessarily found in correspondence of the green autarkic equilibrium. This proves the existence, at the world level, of a trade-off between the environmental condition and the benefits of trade liberalisation. The beneficial effects of free trade are, in fact, to be exclusively imputed to the reduction of negative environmental externalities due to the penetration of the green firm 1 in the domestic market of country 2. As a consequence, the highest possible gain from trade liberalisation calls for $\beta=1$, where the environmental damage is maximum. In the same way, as far as the emission intensity $\beta$ tends to zero, thus nullifying the environmental impact of consumption, autarky becomes the world first best social equilibrium.

\section{Trade policies}

This section describes the effects of trade liberalisation in the case in which the two country governments can effectively implement some stylised trade policy instruments. To this regard, our task is to ascertain whether the latter are bound to (i) expand/restrict the portion of the parameter range in which trade liberalisation is feasible and (ii) distort (lower) the world equilibrium welfare level. As the free trade marginal consumer is always a citizen of country 2, country 1 never has the incentive to restrict imports, which are always null. As a consequence, we limit our analysis to the three following trade policies: an emission tax on imports levied by the government of country 2 and an export subsidy which alternatively applies to the goods produced by firm 1 or 2 . The subsidy is supposed to be financed by a decrease in welfare, while tax revenues are supposed to directly accrue to the social welfare of country 2 . In the following, we first focus on the two options at country 2 government's disposal and then on country 1's government.

\subsection{Imposing a tariff on firm 1's sales}

If country 2's government levies a tariff $\tau>0$ on the volume of the imported green variety, the profits of firm 1 are lowered by an amount equal to $\tau\left(\hat{m}_{T \tau}-\alpha\right)$ and then write as

$$
\pi_{1}^{T \tau}=p_{1}^{T \tau} \hat{m}_{T \tau}-\tau\left(\hat{m}_{T \tau}-\alpha\right)
$$

where $T \tau$ stands for trade with tariff. The social welfare of country 2 is supposed to be augmented by an amount equal to the gross tariff income:

$$
S W_{2}^{T \tau}=\pi_{2}^{T \tau}+C S_{2}^{T \tau}-\beta\left(1-\hat{m}_{T \tau}\right)+\tau\left(\hat{m}_{T \tau}-\alpha\right) .
$$

Any change occur in the definition of all other magnitudes with respect to the free trade case previously described. The equilibrium arising is such that $x_{1}^{T \tau}=0$ and $x_{2}^{T \tau}=1$, 
implying the following marginal consumer's equilibrium location:

$$
\hat{m}_{T \tau}=\frac{3-\tau}{6}
$$

while equilibrium prices are $p_{1}^{T \tau}=1+\frac{2 \tau}{3} ;: p_{2}^{T \tau}=\frac{3+\tau}{3} \cdot{ }^{10}$ From the condition of non negativity of country 2 's imports $\left(\hat{m}_{T \tau}-\alpha>0\right)$ we can derive the maximum admissible level of the tariff $\tau::^{11}$

$$
\bar{\tau}=3-6 \alpha
$$

The objective function of the government of country 2 is then:

$$
\max _{\tau} S W_{2}^{T \tau} \quad \text { s.t. } \quad \tau<\bar{\tau},
$$

which yields:

$$
\tau^{*}=2(1-\alpha)-\beta \quad \forall \alpha \in(0,1 / 2), \beta \in(\max [0,4 \alpha-1], 1) .
$$

For $\tau=\tau^{*}$ the marginal consumer locates at:

$$
\hat{m}_{T \tau}^{*}=\frac{1+2 \alpha+\beta}{6} .
$$

Thus, from (3.4) and (3.6), it follows that, for $\beta \in(0, \max [0,4 \alpha-1])$, country 2's government cannot implement $\tau^{*}$, since $\tau^{*}>\bar{\tau}$; it will then necessarily choose a sub-optimal tariff $\tau=\bar{\tau}$ in order to maximize social welfare. The expressions of other equilibrium magnitudes for $\tau=\tau^{*}$ are reported in B.1. Focusing on the social welfare effects of trade liberalisation in the presence of the optimal tariff $\tau^{*}$, we can state what follows:

Proposition 3 [Welfare with Tariff] If size asymmetry and the emission intensity are both sufficiently high, the optimal tariff delivers social welfare gains with respect to autarky for both countries.

Proof. In order to prove the proposition it is sufficient to observe that:

$$
\begin{gathered}
S W_{2}^{T \tau}-S W_{2}^{A}=\frac{1}{12}\left[\alpha\left(1+7 \alpha+3 \alpha^{2}\right)-\beta(8 \alpha+\beta-2)-2\right]>0 \\
\text { iff } \beta \in(\min [\tilde{\beta}, 1], 1)
\end{gathered}
$$

where $\tilde{\beta}=4 \alpha-1+\sqrt{3(1-\alpha)^{3}}$, while

$$
\begin{aligned}
S W_{1}^{T \tau}-S W_{1}^{A}= & \frac{1}{36}\left[2(1+\beta)^{2}-4 \alpha(1+\beta)-\alpha^{2}(16+9 \alpha)\right]>0 \\
\text { iff } \quad \alpha \in(0,0.239), \quad \beta \in(0,1) & \\
\text { and } & \alpha \in(0.239,0.5), \quad \beta \in\left(\min \left[\alpha-1+\frac{3 \sqrt{\alpha^{2}(2+\alpha)}}{\sqrt{2}}, 1\right], 1\right) .
\end{aligned}
$$

\footnotetext{
${ }^{10}$ While the non negativity of both prices is always verified, full market coverage is now ensured if gross consumer surplus is greater than $s_{M C}^{T \tau}=\frac{1}{36}\left(45+18 \tau+\tau^{2}\right)$, where, again, $s_{M C}^{T \tau}>s_{p}^{A}: \forall \alpha \in$ $(0,1 / 2), \beta \in(0,1), \tau>0$.

${ }^{11}$ For each $\tau>\bar{\tau}$, the model thus predicts a reversal of trade flows with $\hat{m}_{T \tau}<\alpha$. This would formally translate the tariff into a subsidy for firm 2 , which, clearly, is not among the feasible policies available to country 2's government, and would invalidate the definition of the demand system.
} 
Hence, the parameter range in which both countries gain from trade liberalisation necessarily coincides with the one in (3.8), while concerning social welfare at the world level we have that:

$$
\begin{aligned}
& S W^{T \tau}-S W^{A}= \frac{1}{36}\left[5 \alpha^{2}-4+5 \beta(2+\beta)-\alpha(1+28 \beta)\right]>0 \\
& \text { iff } \quad \alpha \in(0,0.4), \quad \beta \in\left(\frac{14 \alpha-5+3 \sqrt{5+\alpha(19 \alpha-5)}}{5}, 1\right)
\end{aligned}
$$

Figure 2 offers a picture of the parameters ranges described above.

[Figure 2 about here]

The foregoing discussion leads the following proposition:

Proposition 4 [Tariff]. The optimal tariff $\tau^{*}$ never succeeds in raising the overall free trade social welfare.

Proof. In order to prove the proposition it suffices to recall the definitions of the overall social welfare differentials with respect to autarky (2.15) and (3.10) and show that

$$
\Delta S W^{T \tau}-\Delta S W^{T}=\frac{1}{36}(2-2 \alpha+5 \beta)(-2+2 \alpha+\beta)
$$

which is strictly negative over the whole parameter range.

This also has an ancillary but relevant consequence. In the range appearing in (3.8), country 2 can effectively implement $\tau^{*}$ as a credible threat in order to extract surplus from country 1, i.e., raising the minimum transfer level necessary to enforce trade liberalisation in the case described in the preceding section. In that case, in fact, the minimum transfer level from country 1 to country 2 is

$$
\underline{T r}_{1,2}^{T}=-\Delta S W_{2}^{A, T}
$$

which is equal to the loss suffered by country 2 in free trade. The tariff allows country 2 to ask for (3.12) to be increased, at most, by the positive amount $\Delta S W_{2}^{A, T \tau}$ such that:

$$
\underline{T r}_{1,2}^{T \tau}=-\Delta S W_{2}^{A, T}+\Delta S W_{2}^{A, T \tau}=S W_{2}^{T \tau}-S W_{2}^{T}=\frac{(2 \alpha+\beta-2)^{2}}{12}
$$

This also implies that the maximum transfer decreases, from $\Delta S W_{1}^{A, T}$ to

$$
\overline{\operatorname{Tr}}_{1,2}^{T \tau}=\Delta S W_{1}^{A, T}-\Delta S W_{1}^{A, T \tau}=\frac{(4 \alpha-\beta-4)(2 \alpha+\beta-2)}{18} .
$$

Since in $\beta \in\left(\min \left[4 \alpha-1+\sqrt{3(1-\alpha)^{3}}, 1\right], 1\right)$ it is always verified that $\overline{\operatorname{Tr}}_{1,2}^{T \tau}>\underline{\operatorname{Tr}}{ }_{1,2}^{T \tau}$, so that there always exists an interval $\underline{T r}_{1,2}^{T \tau}<\operatorname{Tr}<\overline{\operatorname{Tr}}_{1,2}^{T \tau}$ in which country 2 does not implement the Pigouvian tax on imports $\tau^{*}$. As a consequence, irrespective of the fact that it may or not be credibly implemented by the government of country 2, the optimal tariff policy is strictly distortionary, in that it always delivers a lower overall social welfare with respect to the free trade equilibrium. 


\subsection{Subsidising firm 2's sales}

The second policy option for the government of country 2 is a subsidy $\theta_{2}>0$ to firm 2 for each of the $\alpha-\hat{m}_{T \theta}$ units of brown good export to country 1 . The subsidy is obviously defined for all $\hat{m}-\alpha<0$, that is, if the marginal consumer is located in country $1 .{ }^{12} \mathrm{In}$ this case, the profits of firm 2 become:

$$
\pi_{2}^{T \theta_{2}}=p_{2}^{T \theta_{2}} \hat{m}_{T \theta}+\theta_{2}\left(\alpha-\hat{m}_{T \theta_{2}}\right)
$$

where superscript $T \theta_{2}$ stands for trade with subsidy for firm 2. Accordingly, countries' social welfare functions write as

$$
S W_{1}^{T \theta_{2}}=\pi_{1}^{T \theta_{2}}+C S_{1}^{T \theta_{2}}-\beta\left(\alpha-\hat{m}_{T \theta_{2}}\right) ; \quad S W_{2}^{T \theta_{2}}=\pi_{2}^{T \theta_{2}}+C S_{2}^{T \theta_{2}}-\beta(1-\alpha)-\theta_{2}\left(\alpha-\hat{m}_{T \theta_{2}}\right)
$$

From (3.16), equilibrium social welfare of country 2 is supposed to be reduced by an amount equal to the subsidy enjoyed by firm 2. Moreover, the externality now also hurts country 1's social welfare, since a part of consumers switches to the brown good produced by firm 2. Again, the resulting equilibrium is such that $x_{1}^{T \theta_{2}}=0$ and $x_{2}^{T \theta_{2}}=1$, implying the following marginal consumer's equilibrium location:

$$
\hat{m}_{T \theta_{2}}=\frac{3-\theta_{2}}{6}
$$

which is obviously decreasing in $\theta_{2}$, while equilibrium prices are $p_{1}^{T \theta_{2}}=1-\frac{\theta_{2}}{3}$ and $p_{2}^{T \theta_{2}}=$ $1-\frac{2 \theta_{2}}{3}$. Note that both prices are decreasing in $\theta$, because the subsidy strengthens the price competition stemming from trade liberalisation. This obviously happens since firm 2 can now sustain a lower price. From the non-negativity condition on country 1's imports $\left(\hat{m}_{T \theta}-\alpha<0\right)$ we can derive the minimum level of $\theta$ :

$$
\underline{\theta}_{2}=3(1-2 \alpha)
$$

while the non-negativity of both prices is now verified for $\theta_{2} \in\left(0, \frac{3}{2}\right]$. The latter condition, togheter with (3.18), implies that the subsidy policy is necessarily restricted to the range $\alpha \in(1 / 4,1 / 2)$ because for values of $\alpha$ below $1 / 4$ the minimum subsidy $\underline{\theta}_{2}$ exceeds $3 / 2 .{ }^{13}$ The maximisation of social welfare by country 2 's government then yields

$$
\theta_{2}^{*}=2(1-\alpha) \quad \forall \alpha \in(1 / 4,1 / 2), \beta \in(0,1)
$$

and for $\theta_{2}=\theta_{2}^{*}$ the marginal consumer locates at:

$$
\hat{m}_{T \theta_{2}}^{*}=\frac{1+2 \alpha}{6} \text {. }
$$

If the Government of country 2 provides firm 2 with a $\theta_{2}^{*}$ subsidy, we can state what follows:

\footnotetext{
${ }^{12}$ Note that, according to [16], this also implies that the demand system has to be defined anew, in order to account for the trade flow reversal. Nonetheless, this has no consequences on the definition of the marginal consumer's location which is again (2.8).

${ }^{13}$ Full market coverage is now assured if consumer surplus is greater than $s_{M C}^{T \theta_{2}}=$ $\frac{1}{36}[9(5-2 \beta+4 \alpha \beta)-\theta(18-6 \beta-\theta)]$, where $s_{M C}^{T \theta_{2}}>s_{p}^{A} \forall \alpha \in(1 / 4,1 / 2), \quad \beta \in(0,1), \quad \theta \in(0,3 / 2)$.
} 
Proposition 5 [Welfare with Subsidy C2] The long-run effect of trade liberalisation on social welfare consists in: (i) an increase in the welfare of the larger country if the asymmetry in size is sufficiently small, and (ii) a decrease in the welfare the smaller country as well as global welfare, irrespective of size asymmetry and emission intensity.

Proof. In order to prove part (i) of Proposition 1, it suffices to observe that, for $\theta_{2}=\theta_{2}^{*}, \alpha \in(1 / 4,1 / 2)$ and $\beta \in(0,1)$ :

$$
S W_{2}^{\mathbf{T} \theta_{2}}-S W_{2}^{A}=\frac{(2+\alpha)\left(\alpha+3 \alpha^{2}-1\right)}{12}>0 \quad \text { iff } \quad \alpha \in\left(\frac{\sqrt{13}-1}{6} \simeq 0.434,1 / 2\right)
$$

while, concerning part (ii), we have:

$$
\begin{aligned}
& S W_{1}^{\mathbf{T} \theta_{\mathbf{2}}}-S W_{1}^{A}=\frac{1}{36}\{2+30 \beta-\alpha[4+\alpha(16+9 \alpha)]\} \\
& S W^{\mathbf{T} \theta_{\mathbf{2}}}-S W^{A}=\frac{1}{36}[\alpha(5 \alpha-24 \beta-1)+6 \beta-4]
\end{aligned}
$$

both strictly negative over the whole parameter range.

The last claim in Proposition 5 tells us that in our setup, an optimal subsidy is alternatively a not credible or ineffective threat from country 1's standpoint. In fact, for all $\alpha \in(0.434,0.5)$, country 2 may always credibly announce to implement the policy, altough it is clear that she cannot offer a sufficiently large side-payment to country 1's government in order to enforce trade liberalisation. This happens since the subsidy policy always hurts the social welfare at the world level, as compared to autarky. As a consequence, the threat of adopting an optimal subsidy policy is fully equivalent to closing barriers.

It remains to be formally checked if also the subsidy is distortionary:

Proposition 6 [Subsidy C2] . The optimal subsidy $\theta_{2}^{*}$ is always outperformed by the optimal tariff $\tau^{*}$.

Proof. In order to prove the proposition, observe that, from (B.1) and (B.2):

$$
\Delta S W^{T \tau, T \theta_{2}}=S W^{T \theta_{2}}-S W^{T \tau}=\frac{1}{36} \beta(4 \alpha-5 \beta-4)
$$

which is strictly negative over the relevant parameter range $\alpha \in(1 / 4,1 / 2)$. Finally, taking into account Proposition 4, we can write

$$
S W^{T \theta_{2}}<S W^{T \tau}<S W^{T}
$$




\subsection{Subsidising firm 1's sales}

Although the government of country 1 has no incentive to design a tariff policy, it may always susbsidise its own firm. To this regard, we suppose that it may adopt a subsidy $\theta_{1}>0$, formally identical to the one described in Section 3.2. The price incentive is now provided to firm 1 for each of the $\hat{m}-\alpha$ units of green good export to country 2 . In this case, firm 1's profits become:

$$
\pi_{1}^{T \theta_{1}}=p_{1}^{T \theta_{1}} \hat{m}_{T \theta_{1}}+\theta_{1}\left(\alpha-\hat{m}_{T \theta_{1}}\right)
$$

where $T \theta_{1}$ stands for trade with subsidy for firm 1 . Accordingly, countries' social welfare functions now write as

$$
S W_{1}^{T \theta_{1}}=\pi_{1}^{T \theta_{1}}+C S_{1}^{T \theta_{1}}-\theta_{1}\left(\hat{m}_{T \theta_{1}}-\alpha\right) ; \quad S W_{2}^{T \theta_{1}}=\pi_{2}^{T \theta_{1}}+C S_{2}^{T \theta_{1}}-\beta\left(1-\hat{m}_{T \theta_{1}}\right)
$$

The long run again entails the usual $(0 ; 1)$ equilibrium locations of firm 1 and 2 while, in this case we have

$$
\hat{m}_{T \theta_{1}}=\frac{3+\theta_{1}}{6} ; \quad p_{1}^{T \theta_{1}}=1-\frac{2 \theta_{1}}{3} ; \quad p_{2}^{T \theta_{1}}=1-\frac{\theta_{1}}{3} ; \quad \underline{\theta}_{1}=3(1-2 \alpha)
$$

and non-negativity of both prices is verified for $\theta_{1} \in\left(0, \frac{3}{2}\right]$, the subsidy being defined in the same parametric range as in section $3.2, \alpha \in(1 / 4 ; 1 / 2)$. ${ }^{14}$ The optimal equilibrium subsidy

$$
\theta_{1}^{*}=\frac{3(4 \alpha-1)}{4} \quad \forall \alpha \in(1 / 4,1 / 2), \beta \in(0,1)
$$

now entails the following marginal consumer's location

$$
\hat{m}_{T \theta_{1}}^{*}=\frac{3+4 \alpha}{8} \text {. }
$$

If indeed the Government of country 1 provides firm 1 with subsidy $\theta_{1}^{*}$, we can state:

Proposition 7 [Welfare with Subsidy C1] The long-run effect of trade liberalisation on social welfare consists in: (i) an increase in the welfare of the smaller country, (ii) a increase in the welfare the larger country if size asymmetry is sufficiently low and emission intensity is sufficiently high, and (iii) an increase in the social welfare at the world level if emission intensity is high enough.

Proof. Part (i) of Proposition 1 is holds because, for $\theta_{1}=\theta_{1}^{*}, \alpha \in(1 / 4,1 / 2)$ and $\beta \in(0,1)$,

$$
S W_{1}^{\mathbf{T} \theta_{\mathbf{1}}}-S W_{1}^{A}=\frac{9-4 \alpha[\alpha(\alpha-4)+6]}{16}>0
$$

for all $\alpha \in(1 / 4,1 / 2), \beta \in(0,1)$. Part (ii) relies on

$$
\begin{gathered}
S W_{2}^{\mathbf{T} \theta_{\mathbf{1}}}-S W_{2}^{A}=\frac{8 \alpha[2 \alpha(\alpha-4)+11-4 \beta]-37+24 \beta}{64}>0 \\
\text { iff } \quad \alpha \in(0.386,1 / 2), \beta \in(\underline{\beta}, 1)
\end{gathered}
$$

\footnotetext{
${ }^{14}$ Full market coverage is now ensured if consumer surplus is greater than $s_{M C}^{T \theta_{1}}=\frac{1}{36}\left(45-18 \theta+\theta^{2}\right)$, where, again, $s_{M C}^{T \theta_{1}}>s_{p}^{A}: \forall \alpha \in(1 / 4,1 / 2), \beta \in(0,1), \quad \theta_{1} \in(0,3 / 2)$.
} 
where $\underline{\beta}=\frac{8 \alpha[2 \alpha(\alpha-4)+11]-37}{8(4 \alpha-3)}$. Part (iii) is proved by

$$
S W^{\mathbf{T} \theta_{\mathbf{1}}}-S W^{A}=\frac{24 \beta-8 \alpha(1+4 \beta)-1}{64}>0 \quad \text { iff } \beta \in\left(\frac{1+8 \alpha}{8(3-4 \alpha)}, 1\right) .
$$

Then, differently from $\theta_{2}^{*}, \theta_{1}^{*}$ may also be beneficial for country 2 since it strengthens the positive green export effect of trade liberalisation. The range in which both countries gain from trade liberalisation is therefore compatible with a Nash bargaining solution. We will henceforth refer to this equilibrium as $T \theta_{1} b$, where the $b$ stands for bargaining. Figure 3 summarises the claims in Proposition 7

[Figure 3 about here]

Moreover, the comparison with the other scenarios previously described along the world social welfare dimension delivers the following result:

Proposition 8 [Subsidy C1]. The optimal subsidy $\theta_{1}^{*}$ raises the overall free trade social welfare for sufficiently low levels of size asimmetry and emission intensity.

Proof. In order to prove the proposition it is sufficient to observe that, from (B.1) and (B.3):

$$
\begin{gathered}
\Delta S W^{T, T \theta_{1}}=S W^{T \theta_{1}}-S W^{T}=\frac{(4 \alpha-1)(1-4 \alpha+8 \beta)}{64}>0 \\
\text { iff } \alpha \in(0.25,0.5), \beta \in\left(0, \frac{4 \alpha-1}{8}\right) .
\end{gathered}
$$

\subsection{Discussion}

Having described the welfare effects of the three different trade policies, we may now provide a comprehensive picture of the feasible equilibria in the space $(\alpha, \beta)$. First of all, note that, in the range $\alpha \in(0.25,0.5), \beta \in(4 \alpha-1,1)$, the government of country 2 can indeed choose between an optimal tariff and an optimal subsidy. To this regard, and taking into account only the welfare of country 2 , the subsidy outperforms the tariff for sufficiently low emission intensity or sufficiently low asimmetry in size. In fact, by (B.1) and (B.2), we see that

$$
\begin{aligned}
\Delta S W_{2}^{T \tau, T \theta_{2}}= & S W_{2}^{T \theta_{2}}-S W_{2}^{T \tau}=\frac{\beta(8 \alpha-2-\beta)}{12}>0 \\
\text { iff } & \alpha \in(0.25,0.375), \beta \in(4 \alpha-1,8 \alpha-2) \\
\text { or } & \alpha \in(0.375,0.5), \beta \in(4 \alpha-1,1)
\end{aligned}
$$

However, (3.34), although necessary, is not sufficient to prefer the subsidy to the tariff as this would require two more conditions to simultaneously hold. First, both policies 
must be credible, that is, they must generate a country's welfare gain with respect to its autarkic equilibrium level. Second, country 2's gain must go along with an overall welfare gain, so that, alternatively, either (i) both countries gain from trade liberalisation or (ii) a side-payment to country 1 is feasible.

The first of the two conditions is met only by the subsidy. In fact, as one may ascertain by looking at Proposition 3 and 5, only the subsidy grants the larger country a welfare gain with respect to autarky, in the range $\alpha \in(0.434,0.5), \beta \in(4 \alpha-1,1)$, while the tariff necessarily implies a loss.

The second condition holds instead only for the tariff. Note, in fact, that in the region

$$
\alpha \in(0.25,0.4), \beta \in([14 \alpha-5+3 \sqrt{5+\alpha(19 \alpha-5)}] / 5,1)
$$

the tariff exerts a positive effect on the overall welfare with respect to its autakic level, while the subsidy does not.

As a result, in the range $\alpha \in(0.25,0.5), \beta \in(4 \alpha-1,1)$ country 2 will not consider to implement a trade policy since it cannot extract any additional surplus from country 1 , to raise the minimum transfer offered by country 1 in order to enforce trade liberalisation.

Similar arguments hold for the range $\alpha \in(0,0.25), \beta \in(0, \min [\tilde{\beta}, 1])$ where the sole policy option for country 2's government is the optimal tariff $\tau^{*}$. In that case, the tariff never meets the first of the two above conditions. Consequently, the case in which the tariff may be effective in raising the free trade country 2's welfare is limited to the range $\alpha \in(0,0.176), \beta \in(\tilde{\beta}, 1)$.

As to the optimal subsidy $\theta_{1}^{*}$, nothing prevents country 1 from adopting it in the range $\alpha \in(1 / 4,1 / 2)$ in which it is feasible, except the fact that it cannot raise the world welfare with respect to its autarkic level. According to Proposition 7, this happens for $\alpha \in(0.25,0.5), \beta \in\left(0, \frac{1+8 \alpha}{8(3-4 \alpha)}\right)$. Comparing (2.15) and (3.32), we may thus conclude that the subsidy further expands the range in which free trade is beneficial for the global economy. Moreover, according to Proposition 8, in the same range the subsidy delivers the highest possible world welfare, so that it is not a distortionary policy.

Finally, note that the claims in Proposition 2 still hold when free trade is accompanied by a subsidy policy: also for $\alpha>1 / 4$ in fact, the highest social welfare is attained at the green autarkic equilibrium.

Figure 1 resumes the results so far described. In the figure, we identify four areas, each one being identified by the appropriate label.

[Figure 4 about here]

Free trade without any accompanying policy is thus optimal for a limited parameter range. As the asymmetry in size between the two countries decreases, we observe an expansion of the range of $\beta$ in which the autarkic equilibrium is optimal at the world level. The larger country 1 , the greater the green share of the differentiated good consumed at the world level and the lower the environmental benefits of free trade. 


\section{Asymmetric information on $\beta$}

The analysis in Section 3 is based on the hypotesis that the information on the emission intensity $\beta$ is common knowledge for the two governments. If this is the case, we have shown that, whenever trade is enforceable, the equilibrium welfare of the two countries, after side-payments, crucially depens on (i) the value of the intertemporal discount rate $\delta$ of country 1 in (2.16) and (ii) the feasibility of a tariff policy adopted by country 2, which would necessarily raise the minimum side-payment $\underline{\operatorname{Tr}}{ }_{1,2}^{T}$.

Suppose now that only the government of country 2 is able to observe the real extent of the environmental damage suffered by its own inhabitants. This implies that this government may report a fictitious value $\hat{\beta}$ of the emission intensity, so that it faces the following maximisation problem

$$
\max _{\hat{\beta}}{\widehat{S W_{2}}}^{i} \quad \text { s.t. } \quad \hat{\beta}>\bar{\beta}
$$

The maximand $\widehat{S W}_{2}^{i}$ is the ex-post welfare level of country 2, defined as

$$
\widehat{S W}_{2}^{i}=S W_{2}^{j}+\widehat{T R}_{1,2}^{i}
$$

where superscripts $i, j=T, T \tau, T \theta_{1}, T \theta_{1} b$ identify the ranges to which the declared emission level $\hat{\beta}$ and the real level $\beta$ belong. Accordingly, the payment made by country 1 takes the values ${ }^{15}$

$$
\widehat{T R}_{1,2}^{i}= \begin{cases}\widehat{T R}_{1,2}^{T}=S W_{2}^{A}(\hat{\beta})-S W_{2}^{T}(\hat{\beta}) & \forall \alpha \in\left(0, \frac{1}{4}\right), \hat{\beta} \in(\bar{\beta}, \min [\tilde{\beta}, 1]) \\ \underline{\operatorname{Tr}}_{1,2}^{T \tau}(\hat{\beta}) & \forall \alpha \in(0,0.176), \hat{\beta} \in(\tilde{\beta}, 1) \\ \widehat{T R}_{1,2}^{T \theta_{1}}=S W_{2}^{A}(\hat{\beta})-S W_{2}^{T \theta_{1}}(\hat{\beta}) & \forall \alpha \in\left(\frac{1}{4}, \frac{1}{2}\right), \hat{\beta} \in(\bar{\beta}, \min [\underline{\beta}, 1]) \\ \widehat{T R}_{1,2}^{T \theta_{1} b}=\frac{\Delta S W^{A, T \theta_{1}}(\hat{\beta})}{2}-\Delta S W_{2}^{A, T \theta_{1}}(\hat{\beta}) & \forall \alpha \in\left(0.386, \frac{1}{2}\right), \hat{\beta} \in(\underline{\beta}, 1)\end{cases}
$$

Finally, the lower bound of $\bar{\beta}$ in the constraint writes as

$$
\bar{\beta}=\left\{\begin{array}{lll}
\frac{\alpha(1-\alpha)}{2-4 \alpha} & \text { iff } & \alpha<1 / 4 \\
\frac{1+8 \alpha}{8(3-4 \alpha)} & \text { iff } & \alpha>1 / 4
\end{array}\right.
$$

that is, $\hat{\beta}$ must necessarily lie in the range for which free trade (either regime $T$ or $T \theta_{1}$ ) delivers an increase in the overall social welfare. Note that in the first and third case in (3.37) the transfer writes as (3.12) while, in the second one, writes as (3.13). The fourth case corresponds to the area in which both countries gain from trade liberalisation when the government of country 1 chooses to subsidy its firm. As a consequence, this parameter range is compatible with a Nash bargaining solution and the side-payment is set as to equal the social welfare of country 1 to the declared social welfare of country 2 . The behaviour of country 2's governments, i.e., the optimal value of the declared emission intensity $\hat{\beta}^{*}$ is summarised in the following proposition:

\footnotetext{
${ }^{15}$ In the following we suppose that the effective transfer is equivalent to the minimum transfer $\underline{T r}_{1,2}$.
} 
Proposition 9 [Asymmetric information]. In the presence of aysmmetric information on the real level of emission intensity $\beta$, country 2's government always reports the minimum value of $\beta$ compatible with trade liberalisation, i.e. $\hat{\beta}=\bar{\beta}$.

Proof. The proof of the proposition requires to solve the maximisation problem of (3.35) for each of the cases in (3.37). Let's first consider the case $\alpha \in\left(0, \frac{1}{4}\right), \hat{\beta} \in$ $(\bar{\beta}, \min [\tilde{\beta}, 1])$, then, from $(3.35),(3.37),(\mathrm{A} .1)$ and $(\mathrm{A} .2)$ we have that

$$
\begin{aligned}
\widehat{S W}_{2}^{T} & =S W_{2}^{T}+S W_{2}^{A}(\hat{\beta})-S W_{2}^{T}(\hat{\beta}) \\
& =\frac{12 s(1-\alpha)-1-6(\hat{\beta}+\beta)+\alpha[3+\alpha(\alpha-3)+12 \hat{\beta}]}{12},
\end{aligned}
$$

where

$$
\frac{\partial \widehat{S W}_{2}^{T}}{\partial \hat{\beta}}=\frac{2 \alpha-1}{2}
$$

which is independent from the real emission intensity $\beta$ and strictly negative over $\alpha \in$ $(0,1 / 2)$. Accordingly, the maximisation of (3.39) with respect to $\hat{\beta}$ necessarily yields $\hat{\beta}^{*}=\bar{\beta}$. In the second case in (3.37), the government of country 2 may credibly implement a tariff policy, thus raising its minimum side payment to the level $\underline{T r}_{1,2}^{T \tau}$. This implies that (3.36) now writes as

$$
\begin{aligned}
\widehat{S W}_{2}^{T \tau} & =S W_{2}^{T}+\underline{T r}_{1,2}^{T \tau}=S W_{2}^{T}+S W_{2}^{T \tau}(\hat{\beta})-S W_{2}^{T}(\hat{\beta}) \\
& =\frac{12 s(1-\alpha)-3+4 \alpha\left(1+\alpha+\alpha^{2}\right)-\hat{\beta}(4-4 \alpha-\hat{\beta})-6 \beta}{12}
\end{aligned}
$$

where

$$
\frac{\partial \widehat{S W}_{2}^{T \tau}}{\partial \hat{\beta}}=\frac{2 \alpha+\beta-2}{6}
$$

which is strictly positive over $\alpha \in(0,1 / 2)$. In the case in which country 2 undertakes a tariff policy, this implies that the optimal declared emission intensity is $\hat{\beta}^{*}=1$. Anyway, the asymmetric information implies that the government of country 2 may effectively report any value of $\beta \in(\bar{\beta}, 1)$, that is, even values below the threshold $\beta=\tilde{\beta}$. This would obviously dropping the tariff policy and getting (3.39). The government must then compare the maximum social welfare with the tariff $\left(\left.\widehat{S W}_{2}^{T \tau}\right|_{\hat{\beta}=1}\right)$ with the maximum social welfare without it $\left(\left.\widehat{S W}_{2}^{T}\right|_{\hat{\beta}=\bar{\beta}}\right)$. In this respect, from (3.39) and (3.40) we have that:

$$
\left.\widehat{S W}_{2}^{T \tau}\right|_{\hat{\beta}=1}-\left.\widehat{S W}_{2}^{T}\right|_{\hat{\beta}=\bar{\beta}}=\frac{\alpha[8+\alpha(4+3 \alpha)-5]}{12},
$$

which is strictly negative for all $\alpha \in(0,1 / 4)$ so that, in this range, the optimal declared emission intensity is necessarily $\hat{\beta}^{*}=\bar{\beta}$, regardless of the fact the government of country 
2 may or not effectively adopt a tariff policy. The third case in (3.37) entails the following maximand

$$
\begin{aligned}
\widehat{S W}_{2}^{T \theta_{1}} & =S W_{2}^{T \theta_{1}}+S W_{2}^{A}(\hat{\beta})-S W_{2}^{T \theta_{1}}(\hat{\beta}) \\
& =\frac{24 s(1-\alpha)-2-3(3 \hat{\beta}+5 \beta)+2 \alpha[3+\alpha(\alpha-3)+6(\hat{\beta}+\beta)]}{24},
\end{aligned}
$$

where

$$
\frac{\partial \widehat{S W}_{2}^{T \theta_{1}}}{\partial \hat{\beta}}=\frac{4 \alpha-3}{8}
$$

which is strictly negative over $\alpha \in(1 / 4,1 / 2)$, implying, again, $\hat{\beta}^{*}=\bar{\beta}$. It remains to be checked the last perspective in (3.37):

$$
\begin{aligned}
\widehat{S W}_{2}^{T \theta_{1} b} & =S W_{2}^{T \theta_{1}}+\frac{\Delta S W^{A, T \theta_{1}}(\hat{\beta})}{2}-\Delta S W_{2}^{A, T \theta_{1}}(\hat{\beta}) \\
& =\frac{384 s(1-\alpha)-72 \hat{\beta}-5(7+48 \beta)+8 \alpha[4 \alpha(\alpha-3)+3(3+4 \hat{\beta}+8 \beta)]}{384},
\end{aligned}
$$

Here, we have that

$$
\frac{\partial \widehat{S W}_{2}^{T \theta_{1} b}}{\partial \hat{\beta}}=\frac{4 \alpha-3}{16}
$$

still strictly negative. As a consequence, in this case, the maximum welfare ${\widehat{S W_{2}}}^{T \theta_{1} b}$ will be in correspondence of $\hat{\beta}=\beta$ which is the bottom threshold under which trade liberalisation net of the side-payment, entails a loss for country 2. If $\alpha<1 / 4$, the government must compare $\left.\widehat{S W}_{2}^{T \theta_{1} b}\right|_{\hat{\beta}=\underline{\beta}}$ with $\left.\widehat{S W}_{2}^{T \theta_{1}}\right|_{\hat{\beta}=\bar{\beta}}$. From (3.42) and (3.43)

$$
\left.\widehat{S W}_{2}^{T \theta_{1} b}\right|_{\hat{\beta}=\underline{\beta}}-\left.\widehat{S W}_{2}^{T \theta_{1}}\right|_{\hat{\beta}=\bar{\beta}}=\frac{4 \alpha[6+\alpha(\alpha-4)]-9}{32}
$$

strictly negative for all $\alpha \in(1 / 4,1 / 2)$. Therefore, also in this parameter range country 2 always adopts $\hat{\beta}^{*}=\bar{\beta}$.

Proposition 9 has two important implications. First, it tells us that asymmetric information on the relevant parameter $\beta$ rules out any distortionary policy and thus enforces the optimal equilibrium configuration from the standpoint of the overall social welfare. This is opposite to the case made by [25] in which distortionary policies persist only as the optimal response to the information constraint. In their setup, the policymaker which would win from dropping the distortionary policy, may maintain it in order not to run the risk of overcompensating the loser. The second important implication has to do instead with the rent-seeking incentive on the part of country 2 when it cheats on the real value of the emission intensity. This is one of the aspects debated in the following section. 


\section{Trade in the green technology}

In the previous sections we have supposed $\beta$ to be exogenous. This obviously entails the fundamental trade-off between trade liberalisation and environmental and social first best, described in Proposition 2. In the following, we extend the model to encompass tradable green technology in order to endogenise the equilibrium level of $\beta$. To this regard, we adopt a very simple framework, supposing that green technology is exclusively produced by (green) country 1's government at the unitary cost $k$. Moreover, we can write the emission intensity after the abatement $\beta_{a}$ as

$$
\beta_{a}=f(\beta, T)
$$

where $T$ represents the amount of green technology bought by country 2. Accordingly, countries' gain from abatement can be written as

$$
\frac{\partial S W_{i}}{\partial T}=\frac{\partial S W_{i}}{\partial \beta} \cdot \frac{\partial \beta}{\partial T}
$$

where $i=1,2$. The price of technology $\left(p_{T}\right)$ would then range from the minimum level represented by the loss/gain incurred by country 1 plus the production cost, to the maximum level represented by country 2's gain from abatement:

$$
\frac{\partial S W_{2}}{\partial \beta} \cdot \frac{\partial \beta}{\partial T} \geq p_{T} \geq k+\frac{\partial S W_{1}}{\partial \beta} \cdot \frac{\partial \beta}{\partial T}
$$

Suppose now that (3.45) assumes the following linear form:

$$
\beta_{a}=\beta-\gamma \cdot T
$$

It then follows that 3.46 now writes as:

$$
\begin{gathered}
-\gamma \cdot \frac{\partial S W_{2}}{\partial \beta} \geq p_{T} \geq k-\gamma \cdot \frac{\partial S W_{1}}{\partial \beta} \\
\frac{\partial S W_{2}}{\partial \beta}>\frac{\partial S W_{1}}{\partial \beta}
\end{gathered}
$$

is the necessary condition for a $p_{T}>0$ to exist, given an arbitrarily small $k$. As only the government of country 2 can influence the level of emission intensity - by buying technology from country 1 - as a first step we assess its incentives to do so. This amounts to assessing the dynamics of country 2's social welfare with respect to $\beta$. Trade in technology is independent from that in the differentiated good, so that the former may also emerge in the parameter ranges in which autarky is the equilibrium outcome of the model, that is for $\beta<\bar{\beta}$. Accordingly, the first and fourth parameter range of (3.37) have been re-defined in (3.49).

$$
\frac{\partial S W_{2}}{\partial \beta}= \begin{cases}\alpha-1<0 & \forall \alpha \in\left(0, \frac{1}{4}\right), \beta \in(0, \min [\tilde{\beta}, 1]) \\ \frac{4 \alpha+2 \beta-10}{12}<0 & \forall \alpha \in(0,0.176), \beta \in(\tilde{\beta}, 1) \\ \alpha-1<0 & \forall \alpha \in\left(\frac{1}{4}, \frac{1}{2}\right), \beta \in(0, \min [\underline{\beta}, 1]) \\ \frac{4 \alpha-5}{16}<0 & \forall \alpha \in\left(0.386, \frac{1}{2}\right), \beta \in(\underline{\beta}, 1)\end{cases}
$$


where $S W_{2}$ is the equilibrium social welfare of country 2. Note that, since the derivative of $S W_{2}$ with respect to $\beta$ is negative irrespective of the level of $\alpha$ and $\beta$, country 2 always benefits from a decrease in the emission intensity. As to country 1 , we have that

$$
\frac{\partial S W_{1}}{\partial \beta}= \begin{cases}\frac{1}{2}-\alpha>0 & \forall \alpha \in\left(0, \frac{1}{4}\right), \beta \in(0, \min [\tilde{\beta}, 1]) \\ \frac{8(1-\alpha)-\beta}{18}>0 & \forall \alpha \in(0,0.176), \beta \in(\tilde{\beta}, 1) \\ \frac{3-4 \alpha}{8}>0 & \forall \alpha \in\left(\frac{1}{4}, \frac{1}{2}\right), \beta \in(0, \min [\underline{\beta}, 1]) \\ \frac{4 \alpha-5}{16}<0 & \forall \alpha \in\left(0.386, \frac{1}{2}\right), \beta \in(\underline{\beta}, 1)\end{cases}
$$

which implies that, except for the last case (bargaining with $\theta_{1}$ subsidy), the smaller country always looses from a decrease in $\beta$. From (A.2) and (B.3), the social welfare of country 1 is independent of the emission intensity, therefore the results in (3.50) are generated by the change in the transfer to country 2. Moreover, by comparing (3.49) and (3.50) we have that

$$
\left|\frac{\partial S W_{2}}{\partial \beta}\right| \geq\left|\frac{\partial S W_{1}}{\partial \beta}\right| \quad \forall \alpha, \beta
$$

Accordingly, there always exists some $k>0$ such that country 1 gains from selling green technology to country 2 . If country 1 's government fixes the price $p_{T}$ to the maximum level $-\frac{\partial S W_{2}}{\partial \beta}$, in a way it extracts from country 2 the whole additional surplus generated by a decrease in $\beta$, the maximum cost for the green technology writes as $\bar{k}=-\left(\frac{\partial S W_{2}}{\partial \beta}+\frac{\partial S W_{1}}{\partial \beta}\right)$, so that

$$
\bar{k}= \begin{cases}\frac{1}{2} & \forall \alpha \in\left(0, \frac{1}{4}\right), \beta \in(0, \min [\tilde{\beta}, 1]) \\ \frac{7+2(\alpha-\beta)}{8} & \forall \alpha \in(0,0.176), \beta \in(\tilde{\beta}, 1) \\ \frac{5-4 \alpha}{8} & \forall \alpha \in\left(\frac{1}{4}, \frac{1}{2}\right), \beta \in(0, \min [\underline{\beta}, 1]) \\ \frac{4 \alpha-5}{8} & \forall \alpha \in\left(0.386, \frac{1}{2}\right), \beta \in(\underline{\beta}, 1)\end{cases}
$$

and country 1 has the incentive to produce and sell technology if $k \in(0, \bar{k})$. The following proposition contains the most important implications of what stated so far.

Proposition 10 [Green Technology]. If information is symmetric, green technology is traded and the production cost of the latter is sufficiently low, then the green autarkic equilibrium, which corresponds to the world social welfare first best, is always enforced.

Proof. The proof of the proposition with regards to the first and third intervals in (3.51) is straightforward. In fact, according to (3.49), (3.50) and (3.51), technology is traded for $k \in\left(0, \min \left(1 / 2, \frac{5-4 \alpha}{8}\right)\right)$, until the emission intensity of country 2 reaches the lower bound $\bar{\beta}$. As far as country 2 always gets its autarkic equilibrium level of social welfare, its incentive to reduce emissions remains constant and positive below the threshold. On the contrary, the loss for country 1 disappears in autarky. As a consequence, the two countries still trade technology in autarky, for all $k \in\left(0, \frac{\partial S W_{2}^{A}}{\partial \beta}\right)$, until $\beta=0$.

Now take the second case in (3.51). Here, country 2 adopts the optimal tariff $\tau^{*}$ as a threat, the two countries still have the right incentive to trade technology (for $k \in$ $\left.\left(0, \frac{7+2(\alpha-\beta)}{8}\right)\right)$ and therefore $\beta$ surely reaches the lower bound $\beta=\tilde{\beta}$. However, below this 
threshold it is optimal to drop the tariff and country 2 gets $S W_{2}^{A}$. Comparing country 2's level of the social welfare above and below the threshold then yields

$$
\left.S W_{2}^{T \tau}\right|_{\beta=\tilde{\beta}}-S W_{2}^{A}=\frac{(\alpha-1)\left[12 \alpha \sqrt{3(1-\alpha)^{3}}+\alpha(46+\alpha)-11-12 s\right]}{12},
$$

which is strictly negative, so that we must conclude that country 2 still buys technology and thus enforces the green autarkic equilibrium. ${ }^{16}$ Lastly, we consider the case of bargaining with subsidy $\left(T \theta_{1} b\right)$. In this specific case, for $k \in\left(0, \frac{4 \alpha-5}{8}\right)$, the emission intensity is necessarily reduced to $\bar{\beta}$. Anyway, contrary to the case of tariff, the incentive of country 2 to marginally reduce $\beta$ below this threshold disappears, as

$$
\begin{aligned}
& \left.S W_{2}^{T \theta_{1} b}\right|_{\beta=\underline{\beta}}-S W_{2}^{A}= \\
& \frac{219+48 s[3+2 \alpha(4 \alpha-5)]-288 \beta+2 \alpha\{2 \alpha[123+\alpha(4 \alpha-45)-96 \beta]+336 \beta-283\}}{96(4 \alpha-3)}
\end{aligned}
$$

is strictly positive over

$$
\alpha \in\left(\frac{1}{4}, \frac{1}{2}\right), \quad \beta \in(\breve{\beta}, \underline{\beta})
$$

where $\breve{\beta}=\frac{1821-6350 \alpha+7752 \alpha^{2}-3696 \alpha^{3}+448 \alpha^{4}}{1152-2688 \alpha+1536 \alpha^{2}}<\beta$. This would entail that the trade in technology stops at $\beta=\beta$. However, if this were the case, country 1 would loss the profits associated to the shift from $\breve{\beta}$ to $\beta=0$. It could then freely provide technology to country 2 in order to restore the incentive of the latter. This requires that the total cost of free technology does not exceed the additional profits for country 1. This is always verified, since

$$
\begin{aligned}
& \left(\left.S W_{2}^{A}\right|_{\beta=\breve{\beta}}-\left.S W_{2}^{A}\right|_{\beta=0}\right)-k \underline{\beta}= \\
& \quad \frac{2 \alpha\left[1879-4 \alpha\left(537-234 \alpha+8 \alpha^{2}\right)\right]-192 k\{4 \alpha[6+\alpha(\alpha-4)]-9\}-1173}{384(4 \alpha-3)}
\end{aligned}
$$

is strictly positive for $\alpha \in\left(\frac{1}{4}, \frac{1}{2}\right), \beta \in(0, \underline{\beta})$ and $k \in\left(0, \frac{5-4 \alpha}{8}\right)$.

However, one may observe that free trade in the differentiated good is not necessary to prove the claim in proposition 10. In fact, as long as the autarkic social welfare of country 2 is strictly decreasing in $\alpha$, while the autarkic social welfare of country 1 is independent from the emission intensity, there always exists a level of $k>0$ such that countries trade in technology up to $\beta=0$, whatever level of $\beta$ they start from. Moreover, this is equivalent to the results in proposition 10 from the point of view of the distribution of welfare between the two countries, given that country 1 still extracts all the welfare gain that country 2 obtains from the emission abatement. Accordingly, trade liberalisation in the differentiated good, although still welfare-maximising both at the single country and

\footnotetext{
${ }^{16}$ Note that country 1 undoubtedly benefits from a decrease in $\beta$ below the threshold, as, dropping the tariff, the side-payment to country 2 decreases.
} 
at the overall level, only affects country 1's internal distribution of welfare. In fact, in autarky, the consumers and the firm based in 1 may benefit from selling green technology but this necessarily requires the government's mediation. Under free trade, part of the gain is directly accruing to firm 1, as it necessarily penetrates the larger market.

Summing up, the possibility of technology transfer delivers a positive effect on the overall social welfare which outperforms the analogous effect of asymmetric information outlined in proposition 9 (when the sole tradable good was the differentiated one). In fact, while in that case asymmetric information ensures that optimal equilibrium is enforced for any $\alpha$ and $\beta$, the trade in green technology ensures that the world social and environmental first best is always met.

We may now ask what is the effect of asymmetric information on $\beta$ in the setup of this section. This is summarised in the following proposition.

Proposition 11 [Asymmetric information and green technology]. If green technology is tradable and free trade in the differentiated good is an equilibrium, asymmetric information prevents country 2 to buy green technology.

Proof. Differentiating the ex-post social welfare level of country $2^{17}$ with respect to the real value of emission intensity $\beta$, we get

$$
\frac{\left.\partial \widehat{S W}_{2}\right|_{\hat{\beta}=\bar{\beta}}}{\partial \beta}= \begin{cases}-\frac{1}{2}<0 & \forall \alpha \in\left(0, \frac{1}{4}\right), \beta \in(\bar{\beta}, 1) \\ \frac{4 \alpha-5}{8}<0 & \forall \alpha \in\left(\frac{1}{4}, \frac{1}{2}\right), \beta \in(\bar{\beta}, 1)\end{cases}
$$

From (3.56) one can conclude that, whenever trade in the differentiated good is an equilibrium, country 2's governement still has the incentive to buy green technology and reduce the level of emission intensity to $\bar{\beta}$. However, from (3.49) and (3.56), these incentives are always weaker if compared to the symmetric information case. This implies that trade would occur in a narrower range of the unitary $\operatorname{cost} k$, i.e., for all $\alpha$ and $\beta$, the cost upper bound $\bar{k}$ is necessarily lower. Moreover, since

$$
\lim _{\beta \rightarrow \bar{\beta}} \widehat{S W}_{2}=S W_{2}^{A}
$$

we can say that, for any $p_{\text {tech }}<\frac{\left.\partial \widehat{S W}_{2}\right|_{\hat{\beta}=\bar{\beta}}}{\partial \beta}$, country 2 always trades its informational rent for a lower level of the environmental damage. Note that this also implies that the long run would always entail the green autarkic equilibrium. Once reached the autarkic equilibrium range, in fact, parameter $\beta$ does not affect the maximum price level for green technology $\left(\frac{\partial S W_{2}^{A}}{\partial \beta}=\alpha-1\right)$ anymore so that asymmetric information plays no role. Accordingly, from Proposition 10, we know that, provided a sufficiently low $k$, the two countries will go on trading below the threshold $\bar{\beta}$, until $\beta=0$, irrespectively of the level of $\alpha$.

However, since country 1 does not observe the real level of $\beta$, it may set the price prevailing in the symmetric case, that is $p_{\text {tech }}=-\frac{\left.\partial S W_{2}\right|_{\beta=\bar{\beta}}}{\partial \beta}=1-\alpha$. Country 2 would then buy technology only if

$$
\gamma=\left.S W_{2}^{A}\right|_{\beta=0}-\left.\widehat{S W}_{2}\right|_{\hat{\beta}=\bar{\beta}}-\beta \cdot p_{\text {tech }}
$$

is strictly positive. Evaluating (3.57) in the four relevant intervals $T \tau, T, T \theta_{1}, T \theta_{1} b$ yields:

\footnotetext{
${ }^{17}$ To this regard, see the proof of Proposition 9.
} 
$[T \tau] \quad \gamma=\frac{8-28 \alpha-13 \alpha^{2}+126 \alpha^{3}-81 \alpha^{4}-48 \alpha^{5}+24 \beta(2 \alpha-1)^{3}}{48(1-2 \alpha)^{2}}<0$

$[T] \quad \gamma=\frac{\alpha-\alpha^{2}-2 \beta+4 \alpha \beta}{4}<0$

$\left[T \theta_{1}, T \theta_{1} b\right] \quad \gamma=\frac{1+6 \alpha+8 \beta(4 \alpha-3)}{64}<0$

which implies the claim in the proposition.

\section{Concluding remarks}

We have investigated the welfare effect of free trade in a framework of spatial competition á la Hotelling. Our setup combines different features of the models developed in the vast literature dealing with the interplay between trade and the environment. In particular, we have outlineed an asymmetric world, where countries' population size is negatively correlated to per-capita income and environmental awareness. Accordingly, the larger among the two countries hosts the only brown firm in the economy and - in autarky - its inhabitants are the only ones suffering from a negative externality stemming from consumption. We have shown that this framework delivers, as a first result, a fundamental trade-off between the overall advantages of trade liberalisation and the degree of greenness of the world economy: free trade may represent a first best equilibrium only if a sufficiently large share of the world population is suffering from pollution in autarky.

Our analysis has taken into account three additional analytical dimensions. The first one is pivoted on the efficiency of trade policies. Looking at the design of such instruments, we have found that, if countries are sufficiently different in size, our framework does not support the adoption of any policy to accompany the opening of trade. In the remaining cases, i.e., for (almost) symmetric country sizes, an export subsidy in favour of the green firm may be instead required to ensure the bilateral opening to trade. The second extension concerns the role of asymmetric information on the equilibrium outcomes. We encompass this asymmetry by assuming that the government of the larger (brown) country avails of some private information on emission intensity. This is shown to have effects only on the distribution of the gains stemming from trade liberalisation: as far as the government can declare a lower level of environmental damage, it intentionally underestimates the beneficial effects of green imports from the smaller country and may demand a larger share of the overall free trade welfare gain in order to open commercial frontiers. However, things change when considering the third analytical dimension, consisting in the endogenisation of the emission intensity via technology transfer. In this case, we show that, if information is symmetric, countries have an incentive to trade in green technology until the externality disappears altogether, which represents the first best. Otherwise, if information is asymmetric, the brown country sistematically trades emission abatement for its informational rent. 


\section{References}

[1] Antweiler, W., Copeland, B. R., Taylor, M. S., 2001. Is free trade good for the environment? American Economic Review 91 (4), 877-908.

[2] Bagwell, K., Staiger, R. W., 2001. Domestic policies, national sovereignty, and international economic institutions. The Quarterly Journal of Economics 116 (2), 519-562.

[3] Bansal, S., Gangopadhyay, S., 2003. Tax/subsidy policies in the presence of environmentally aware consumers. Journal of Environmental Economics and Management 45 (2, Supplement), 333-355.

[4] Brainard, S. L., Martimort, D., 1997. Strategic trade policy with incompletely informed policymakers. Journal of International Economics 42 (1), 33-65.

[5] Clemenz, G., 2010. Eco-labeling and horizontal product differentiation. Environmental and Resource Economics 45, 481-497.

[6] Cole, M. A., 2004. Trade, the pollution haven hypothesis and the environmental Kuznets curve: examining the linkages. Ecological Economics 48, 71-81.

[7] Cole, M. A., Elliot, R. J. R., 2003. Determining the trade-environment composition effect: the role of capital, labor and environmental regulations. Journal of Environmental Economics and Management 46(3), 363-383.

[8] Conrad, K., 2005. Price competition and product differentiation when consumers care for the environment. Environmental and Resource Economics 31 (1), 1-19.

[9] Copeland, B. R., Taylor, M. S., 2003. Trade and the Environment: Theory and Evidence. Princeton University Press.

[10] Engel, S., 2004. Achieving environmental goals in a world of trade and hidden action: the role of trade policies and eco-labeling. Journal of Environmental Economics and Management 48 (3), 1122-2201145

[11] Eriksson, C., 2004. Can green consumerism replace environmental regulation? a differentiated-products example. Resource and Energy Economics 26 (3), 281-293.

[12] Espinola-Arredondo, A., Zhao, H., 2012. Environmental policy in a linear city model of product differentiation. Environment and Development Economics 17 (4), 461-477.

[13] Fisher-Vanden, K., Ho, M. S., Technology, development, and the environment. Journal of Environmental Economics and Management 59 (1), 94-108.

[14] Frankel, J., Rose, A., 2005. Is trade good or bad for the environment? sorting out the causality. Review of Economics and Statistics 87 (1), 85-91.

[15] Friedman, J. W., 1971. A non-cooperative equilibrium for supergames. Review of Economic Studies 38 (113), 1-12. 
[16] Gori, G. F., Lambertini, L., 2013. Trade Liberalisation between asymmetric countries with environmentally concerned consumers. Regional Science and Urban Economics 43 (4), 549-560.

[17] Hatzipanayotou, P., Lahiri, S., Michael, M., S., 2002. Can cross-border pollution reduce pollution?. Canadian Journal of Economics/Revue canadienne d'économique $35(4), 805-818$.

[18] Haupt, A., 2006. Environmental policy in open economies and monopolistic competition. Environmental and Resource Economics 33, 143-167.

[19] Kerr, S., Newell, R., G., 2003. Polic-Induced Technology Adoption: Evidence from the US Lead Phasedown. Journal of Industrial Economics, 51 (3), 317-343.

[20] Lambertini, L., 1997. Trade liberalization may be harmful under endogenous differentiation. Osaka City University Economic Review 33 (1), 237-254.

[21] Lovely, M., Popp, D., 2011. Trade, technology, and the environment: Does access to technology promote environmental regulation? Journal of Environmental Economics and Management 61 (1), 16-35.

[22] Ludema, R., Wooton, I., 1997. International trade rules and environmental cooperation under asymmetric information. International Economic Review 38 (3), 605-625.

[23] Managi, S., Hibiki, A., Tsurumi, T., 2009. Does trade openness improve environmental quality? Journal of Environmental Economics and Management 58 (3), 346-363.

[24] McAusland, C., 2008. Trade, politics, and the environment: Tailpipe vs. smokestack. Journal of Environmental Economics and Management 55 (1), 52-71.

[25] Mitchell, M. F., Moro, A., 2006. Persistent distorsionary policies with asymmetric information. The American Economic Review 96 (1), 387-393.

[26] Moraga-González, J. L., Padrón-Fumero, N., 2002. Environmental policy in a green market. Environmental and Resource Economics 22, 419-447.

[27] Nannerup, N., 1998. Strategic environmental policy under incomplete information. Environmental and Resource Economics 11(1), 61-78.

[28] Neary, J., 2006. International trade and the environment: Theoretical and policy linkages. Environmental and Resource Economics 33 (1), 95-118.

[29] Popp, D., 2010. Exploring links between innovation and diffusion: adoption of NOx control technologies at US coal-fired power plants. Environmental and Resource Economics 45 (3), 319-352.

[30] Rodríguez-Ibeas, R., 2007. Environmental product differentiation and environmental awareness. Environmental and Resource Economics 36 (2), 237-254. 
[31] Snyder, L., D., Miller, N., H., Stavins, R., N., 2003. The effects of environmental regulation on technology diffusion: the case of chlorine manufacturing. American Economic Review 93 (2), 431-435.

[32] Tabuchi, T., Thisse, J.-F., 1995. Asymmetric equilibria in spatial competition. International Journal of Industrial Organization 13 (2), 213-227.

[33] Taylor, M., 2005. Unbundling the pollution haven hypothesis. BE Journal of Economic Analysis \& Policy, 4(2).

[34] Tharakan, J., Thisse, J.-F., 2002. The importance of being small. or when countries are areas and not points. Regional Science and Urban Economics 32 (3), 381-408.

[35] Yakita, A., Yamauchi, H., 2011. Environmental awareness and environmental r\&d spillovers in differentiated duopoly. Research in Economics 65 (3), 137-143. 


\section{A Autarky and free trade}

\section{A.1 Autarkic equilibrium}

The autarkic equilibrium definitions of other relevant magnitudes are:

$p_{1}^{A}=s-\frac{1}{4} \alpha^{2} ; \quad p_{2}^{A}=s-\frac{1}{4}(1-\alpha)^{2} ;$

$\pi_{1}^{A}=\frac{\alpha}{4}\left(4 s-\alpha^{2}\right) ; \quad \pi_{2}^{A}=\frac{1-\alpha}{4}\left[4 s-(1-\alpha)^{2}\right] ;$

$T C_{1}^{A}=\frac{1}{12} \alpha^{3} ; \quad T C_{2}^{A}=\frac{1}{12}(1-\alpha)^{3} ;$

$C S_{1}^{A}=\frac{1}{6} \alpha^{3} ; \quad C S_{2}^{A}=\frac{1}{6}(1-\alpha)^{3}$.

$S W_{1}^{A}=\alpha\left(s-\frac{1}{12} \alpha^{2}\right) ; \quad S W_{2}^{A}=(1-\alpha)\left[s-\frac{1}{12}(1-\alpha)^{2}-\beta\right]$.

\section{A.2 The free trade equilibrium}

Remaining equilibrium magnitudes are:

$T C_{1}^{T}=\frac{\alpha^{3}}{3} ; \quad T C_{2}^{T}=\frac{1}{12}\left(1-4 \alpha^{3}\right) ;$

$C S_{1}^{T}=\alpha\left(s-1-\frac{1}{3} \alpha^{2}\right) ; \quad C S_{2}^{T}=s(1-\alpha)+\frac{1}{3}\left(3 \alpha+\alpha^{3}-\frac{13}{4}\right) ;$

$S W_{1}^{T}=\frac{1}{2}-\alpha(1-s)-\frac{\alpha^{3}}{3} ; \quad S W_{2}^{T}=s(1-\alpha)+\alpha+\frac{\alpha^{3}}{3}-\frac{\beta}{2}-\frac{7}{12}$.

\section{B Trade policy}

\section{B.1 Optimal tariff $\tau^{*}$}

Free trade equilibrium, relevant magnitudes for $\tau=\tau^{*}$ :

$p_{1}^{T \tau}=\frac{1}{3}(7-4 \alpha-2 \beta) ; \quad p_{2}^{T \tau}=\frac{1}{3}(5-2 \alpha-\beta) ;$

$\pi_{1}^{T \tau}=\frac{1}{18}\left[-32 \alpha^{2}+(1+\beta)^{2}+2 \alpha(20-7 \beta)\right] ; \quad \pi_{2}^{T \tau}=\frac{1}{18}(5-2 \alpha-\beta)^{2} ;$

$T C_{1}^{T \tau}=\frac{\alpha^{3}}{3} ; \quad T C_{2}^{T \tau}=\frac{1}{36}\left[3-12 \alpha^{3}+(2-2 \alpha-\beta)^{2}\right]$

$C S_{1}^{T \tau}=\frac{\alpha[3 s+(4-\alpha) \alpha+2 \beta-7]}{3} ;$

$C S_{2}^{T \tau}=\frac{36 s(1-\alpha)+4 \alpha[28-\alpha(11-3 \alpha)]+14 \beta-20 \alpha \beta+\beta^{2}-71}{36} ;$

$S W_{1}^{T \tau}=\frac{1}{18}\left[2 \alpha(9 s-\beta-1)-8 \alpha^{2}-6 \alpha^{3}+(1+\beta)^{2}\right] ;$

$S W_{2}^{T \tau}=\frac{1}{12}\left[12 s(1-\alpha)+4 \alpha\left(1+\alpha+\alpha^{2}\right)-10 \beta+4 \alpha \beta+\beta^{2}-3\right]$. 


\section{B.2 Optimal subsidy for firm 2's sales $\left(\theta_{2}^{*}\right)$}

Free trade equilibrium, relevant magnitudes for $\theta_{2}=\theta_{2}^{*}$ :

$$
\begin{aligned}
& p_{1}^{T \theta_{2}}=\frac{1}{3}(1+2 \alpha) ; \quad p_{2}^{T \theta_{2}}=\frac{1}{3}(4 \alpha-1) ; \\
& \pi_{1}^{T \theta_{2}}=\frac{1}{18}(1+2 \alpha)^{2} ; \quad \pi_{2}^{T \theta_{2}}=\frac{1}{18}[4 \alpha(13-8 \alpha)-11] ; \\
& T C_{1}^{T \theta_{2}}=\frac{\alpha^{3}}{3} ; \quad T C_{2}^{T \theta_{2}}=\frac{1}{36}\left[7+4 \alpha\left(\alpha-3 \alpha^{2}-2\right)\right] ; \\
& C S_{1}^{T \theta_{2}}=\frac{\alpha\left[3 s-(1+\alpha)^{2}\right]}{3} ; \\
& C S_{2}^{T \theta_{2}}=s(1-\alpha) \frac{1+4 \alpha[\alpha(7+3 \alpha)-8]}{36} ; \\
& S W_{1}^{T \theta_{2}}=\frac{1+3 \beta-2 \alpha[1-9 s+\alpha(4+3 \alpha)+6 \beta]}{18} ; \\
& S W_{2}^{T \theta_{2}}=s(1-\alpha)+\frac{\alpha\left(1+\alpha+\alpha^{2}+3 \beta\right)}{3}-\frac{1}{4}-\beta .
\end{aligned}
$$

\section{B.3 Optimal subsidy for firm 1's sales $\left(\theta_{1}^{*}\right)$}

Free trade equilibrium, relevant magnitudes for $\theta_{1}=\theta_{1}^{*}$ :

$$
\begin{aligned}
& p_{1}^{T \theta_{1}}=\frac{3}{2}-2 \alpha ; \quad p_{2}^{T \theta_{1}}=\frac{5}{4}-\alpha ; \\
& \pi_{1}^{T \theta_{1}}=\frac{9+16 \alpha(3-5 \alpha)}{32} ; \quad \pi_{2}^{T \theta_{1}}=\frac{(5-4 \alpha)^{2}}{32} ; \\
& T C_{1}^{T \theta_{1}}=\frac{\alpha^{3}}{3} ; \quad T C_{2}^{T \theta_{1}}=\frac{19-8 \alpha\left(3-6 \alpha+8 \alpha^{2}\right)}{192} ; \\
& C S_{1}^{T \theta_{1}}=\frac{\alpha[6 s+2 \alpha(6-\alpha)-9]}{6} ; \quad C S_{2}^{T \theta_{1}}=s(1-\alpha) \frac{8 \alpha\left(69-42 \alpha+8 \alpha^{2}\right)-277}{192} ; \\
& S W_{1}^{T \theta_{1}}=\alpha\left(s-\frac{3}{2}\right)+\frac{9}{16}+\alpha\left(\alpha-\frac{\alpha^{2}}{3}\right) ; \\
& S W_{2}^{T \theta_{1}}=s(1-\alpha) \frac{8 \alpha\left(39-30 \alpha+8 \alpha^{2}+12 \beta\right)-127-120 \beta}{192} .
\end{aligned}
$$




\section{Graphical Appendix}

Figure 1: Welfare effects of trade liberalisation, parameters' ranges

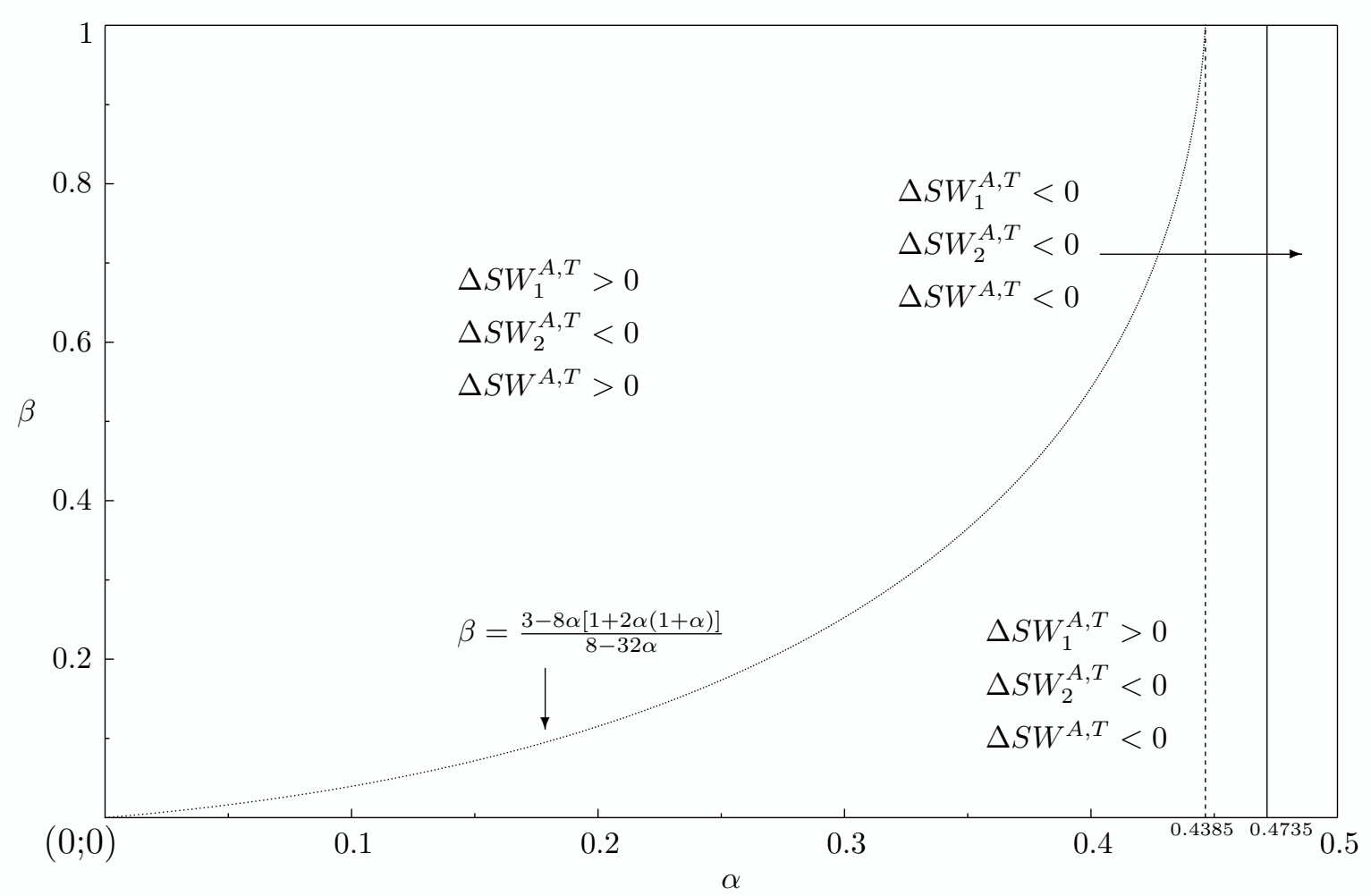


Figure 2: Welfare effects of trade liberalisation with $\tau^{*}$, parameters' ranges

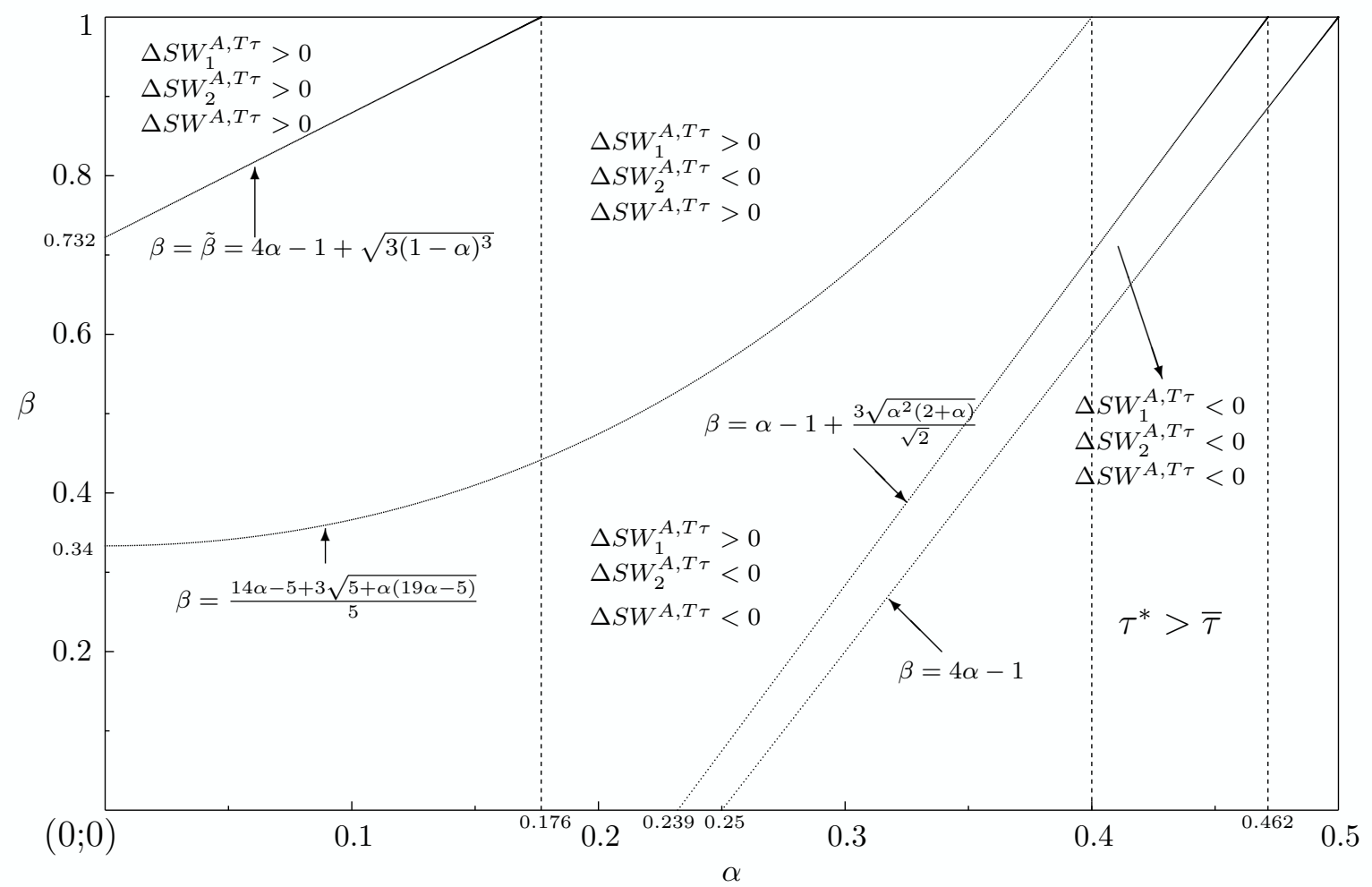


Figure 3: Welfare effects of trade liberalisation with $\theta_{1}$, parameters' ranges

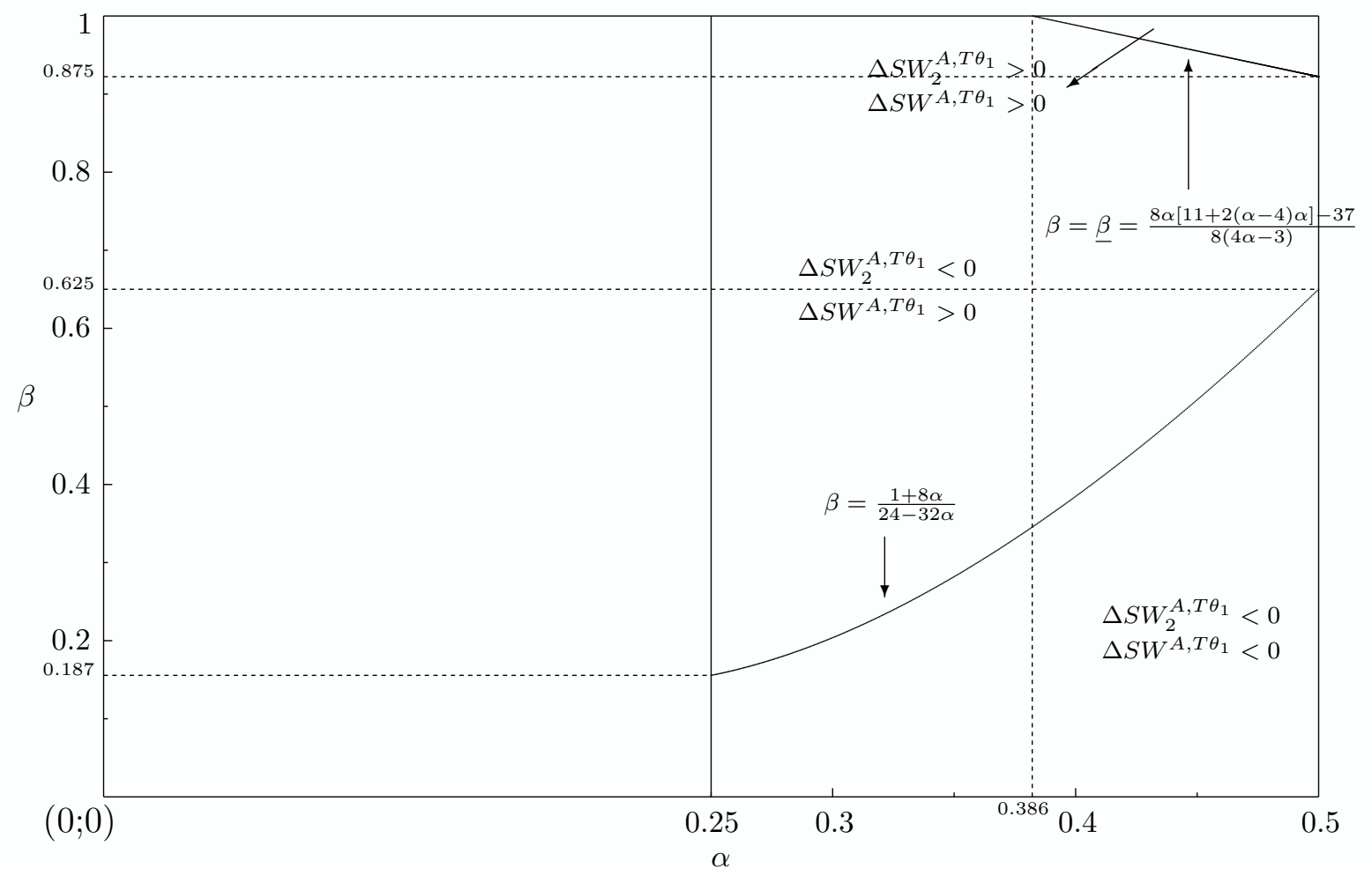


Figure 4: Equilibria, parameters' ranges

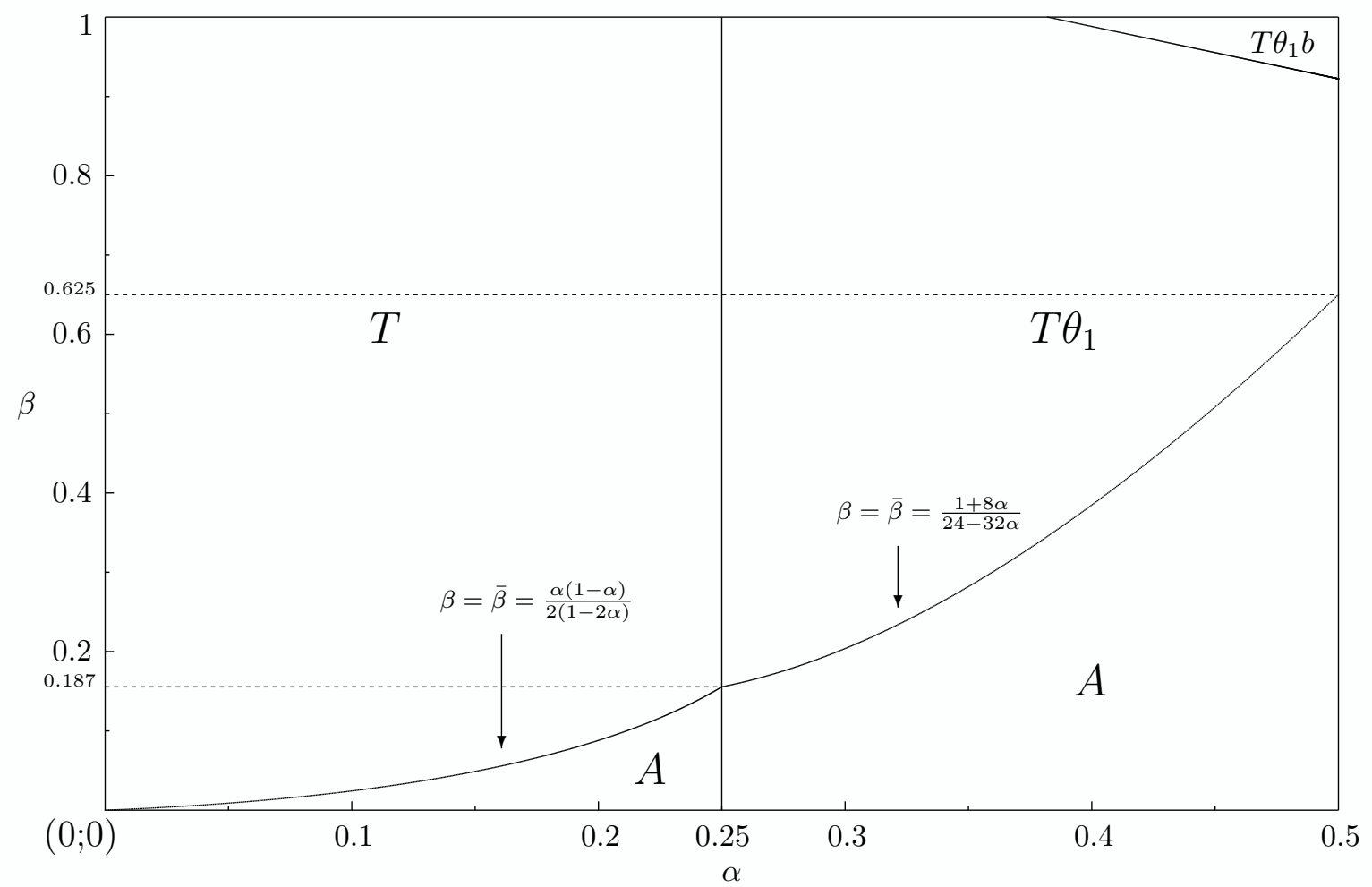




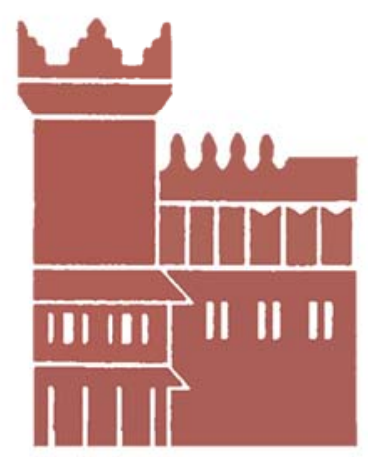

Alma Mater Studiorum - Università di Bologna DEPARTMENT OF ECONOMICS

Strada Maggiore 45

40125 Bologna - Italy

Tel. +39051 2092604

Fax +390512092664

http://www.dse.unibo.it 